\title{
LA INFLUENGIA DE LOS DERECHOS FUNDAMENTALES EN EL ORDENAMIENTO: SU DIMENSIÓN OBJETIVA
}

\author{
CONSTITUTIONAL RIGHTS INFLUENCE IN LEGAL SYSTEM: \\ HIS OBJECTIVE DIMENSION
}

\section{Francisco M. MORA SIFUeNTES*}

RESUMEN: Los derechos fundamentales han adquirido una centralidad indubitable en las modernas democracias constitucionales. Ello puede apreciarse en las decisiones de los tribunales, así como en los desarrollos que la dogmática de los derechos ha ido acuñando desde la segunda mitad del siglo XX gracias, en parte, a la influyente jurisprudencia del Tribunal Constitucional Federal alemán. El "efecto de irradiación", los deberes de protección a cargo del Estado y la eficacia entre particulares, son figuras primordiales de toda teoría de los derechos fundamentales en el marco del constitucionalismo jurídico contemporáneo, tanto en su dimensión nacional como en la internacional. Este trabajo analiza dichas figuras con la finalidad de proporcionar herramientas dogmáticas a los operadores jurídicos para su comprensión. Concluye con unas breves reflexiones y una propuesta para futuras investigaciones.

Palabras clave: derechos fundamentales, efecto de irradiación, deberes de protección a cargo del Estado, eficacia entre particulares, neoconstitucionalismo.
ABSTRACT: Constitutional rights have certainly become central to modern constitutional democracies. This centrality is clear in relation both to courts decisions and to theoretical developments of rights since the second half of the twentieth century, -partly, thanks to the influential case law of the German Federal Constitutional Court. The "effect of irradiation", State protection duties and the horizontal effect (Drittwirkung) are key elements to any theory of constitutional rights whitin the framework of contemporary legal constitutionalism, both in the State-nation and in the international order. This paper seeks to provide tools for legal practitioners. For this purpose, the above mentioned elements will be analyzed in a way that could be properly understood. Some thoughts will provided for further research.

Keywords: Constitutional rights, irradiation effect, State protection duties, horizontal effect, neo-constitucionalism

* Profesor-investigador de tiempo completo, Universidad de Guanajuato, Departamento de Derecho. División de Derecho, Política y Gobierno; candidato al SNI-Conacyt. Contacto:fm.mora@ugto.mx

Boletín Mexicano de Derecho Comparado, nueva serie, año XLIX, núm. 150, septiembre-diciembre de 2017, pp. 1215-1258

Esta obra está bajo una Licencia Creative Commons Atribución-NoComercial-SinDerivar 4.0 Internacional, IIJ-UNAM. 
SuMARIO: I. Introducción. II. Derechos fundamentales y constitucionalismo contemporáneo. III. Derechos "por todas partes" y al mismo tiempo: su fuerza expansiva. IV. Deberes de protección a cargo del Estado. V. La vigencia de los derechos fundamentales en las relaciones entre particulares. VI. A modo de conclusión.

\section{INTRODUCGIÓN}

Uno de los temas centrales de la teoría jurídica es el estudio sistemático de los derechos fundamentales considerados como derecho positivo. Desde dicha perspectiva, podemos reconocer al menos dos enfoques a su objeto de estudio: un punto de vista externo por el cual se estudian las relaciones y dimensiones tanto ética como política, que subyacen a los derechos fundamentales; es decir, se aborda la propuesta moral y del poder político que opera tras la positivación de los derechos y sin los cuales estos son incomprensibles. ${ }^{1}$ Desde el otro punto de vista, denominado interno, se estudian las funciones que los derechos desempeñan en el interior del ordenamiento jurídico. Este último supone defender la idea de que los derechos se presentan, al menos, de dos maneras: como técnica al servicio de la protección del individuo (función subjetiva que se corresponde, de alguna manera, con las primeras formulaciones históricas de los derechos), o bien como criterios de ordenación (función objetiva), desarrollada en el marco del constitucionalismo contemporáneo o neoconstitucionalismo. ${ }^{2}$

Agradezco las observaciones formuladas por el dictaminador del $B M D C$ que me ayudaron a mejorar sustancialmente la presentación final de este texto. Por el mismo motivo, a los miembros del Programa de Investigaciones Jurídicas de la DDPG; especialmente a la doctora Teresita Rendón-Huerta Barrera por su invitación a discutir una primera versión. Presenté un texto más consolidado como ponencia en el marco del XIII Congreso Iberoamericano de Derecho Constitucional organizado por la UNAM con motivo del Centenario de la Constitución Mexicana de 1917 en el Palacio de Minería.

1 Es la denominada perspectiva "dualista”. Véanse Ansuátegui Roig, Francisco Javier, Poder, ordenamiento jurídico, derechos, Madrid, Dykinson, 1997; De Asís Roig, Rafael, Sobre el concepto y fundamento de los derechos. Una perspectiva dualista, Madrid, Dykinson, 2000; y, fundamentalmente, Barranco Avilés, María del Carmen, La teoría jurídica de los derechos, Madrid, Dykinson, 2000.

2 A estas alturas parece difícil seguir utilizando el neologismo sin la advertencia de que, dada su profusión, va en camino a quedarse con apenas una capacidad explicativa. Sin embargo, sigue siendo útil acudir a trabajos como los de Comanducci, Paolo, "Formas de (neo) constitucionalismo: un análisis metateórico", Isonomía, núm. 16, 2002, pp. 89-112; Prieto, Luis, "Sobre el neoconstitucionalismo y sus implicaciones", en id., Fusticia constitu-

Esta obra está bajo una Licencia Creative Commons

Atribución-NoComercial-SinDerivar 4.0 Internacional, IIJ-UNAM.

Boletín Mexicano de Derecho Comparado, núm. 150, pp. 1215-1258 
Fue concretamente en Alemania donde adquirió identidad este modelo o forma de entenderlos. Allí, como señala Erns-Wolfgan Böckenforde, la concepción actual de los derechos fundamentales

se caracteriza por una doble calificación... Por un lado, se conciben como derechos subjetivos de libertad, dirigidos al Estado, del titular de los derechos fundamentales, y, por otro - y al mismo tiempo-, como normas objetivas de principios (objektive grundsatznormen) o decisiones axiológicas (wertentscheidungen) que tienen validez para todos los ámbitos del Derecho. ${ }^{3}$

La cualificación de los derechos como normas objetivas de "principios" o "decisiones axiológicas" constituye un desarrollo bajo la Ley Fundamental, no un dato previo a ella. Su descubrimiento y desarrollo data de mediados de los años cincuenta, y, según el mismo autor, "se encuentra en conexión con la discusión inevitable y obligada tras el derrumbamiento del Régimen Nacional Socialista y el fracaso del positivismo jurídico". ${ }^{4}$

Böckenforde sistematiza, además, los cambios que esta concepción ha supuesto para la teoría y la dogmática. Quien fuera juez del Tribunal Constitucional Federal alemán nos dice que las modificaciones más importantes en la forma de comprender los derechos son las siguientes: en lo que respecta a la función dogmático-jurídica, se afirma que el derecho no puede ser descrito como un modelo puro de reglas; en la función teoréticoestatal, los derechos fundamentales adquieren "deberes" correlativos del poder político; y, finalmente en la función teorético-constitucional, señala que se produce una "judicialización" del ordenamiento. ${ }^{5}$ Por otra parte, Konrad Hesse afirma que por esa doble función los derechos aparecerán ya no sólo como abstenciones que el poder público debe guardar a fin de no lesionarlos, sino también como "obligaciones positivas" de llevar a cabo

cional y derechos fundamentales, Madrid, Trotta, 2003, pp. 101-136; o a los contenidos en el apartado II de Carbonell, Miguel y García Jaramillo, Leonardo (eds.), El canon neoconstitucional, Madrid, Trotta, 2010, pp. 153 y ss.

3 Böckenforde, Erns-Wolfgan, "Sobre la situación de la dogmática de los derechos fundamentales tras 40 años de Ley Fundamental", en $i d$., Escritos sobre derechos fundamentales, trad. J. Requejo e I. Villaverde, Baden-Baden, Nomos, 1993, p. 95.

4 Ibidem, p. 105. Esta afirmación necesitaría precisar a qué tipo de positivismo jurídico se hace referencia.

5 Ibidem, pp. 126-131. 
todo aquello que sirva a su realización, "incluso cuando no conste una pretensión subjetiva de los ciudadanos". ${ }^{6}$

Pues bien, teniendo en cuenta el anterior esquema, en el presente trabajo me propongo analizar algunas manifestaciones de la influencia de los derechos en la totalidad del ordenamiento. Para abordar esta cuestión, en un primer momento, estimo necesario vincular el desarrollo de la vertiente objetiva al paradigma de la Constitución normativa, la rematerialización del derecho y de su garantía jurisdiccional, que es el preciso marco en el que se inserta. Posteriormente, me referiré al "efecto de irradiación" de los derechos y aludiré a los llamados "deberes de protección" que los derechos fundamentales imprimen a los poderes públicos. Luego, trataré el tema de su vigencia en las relaciones entre particulares para concluir con consideraciones generales.

Sin embargo, una advertencia se impone: si decimos que por la dimensión objetiva los derechos se tienen con relación a su carácter de normas y su función en el sistema jurídico en su conjunto y, sobre todo, a las obligaciones de protección independientemente de que exista alguna pretensión individual, debemos tener claro que cada uno de los temas a abordar presentan, respecto a determinados elementos, mayores puntos de conexión con lo que Hesse y parte de la doctrina constitucional entiende por vertiente objetiva. Es decir, habrá casos donde con mayor claridad se hace patente la desvinculación respecto de sus titulares (dimensión subjetiva) y, con ello también, las tensiones que se dan entre ambas dimensiones. Intentar arrojar alguna luz a este respecto es una de las pretensiones principales de este trabajo.

\section{DeREGhos FUndamentales Y GONSTITUCIONALISMO CONTEMPORÁNEO}

Para comenzar debe recordarse la transformación que ha acontecido en varios ordenamientos jurídicos de nuestro entorno. Básicamente el cambio se ubica a nivel constitucional, y se ha aludido como el paradigma de la "rematerialización del derecho", en el que se afirma la fuerza norma-

\footnotetext{
6 Hesse, Konrad, "Significado de los derechos fundamentales", en Benda, E. et al., Manual de derecho constitucional, 2a. ed., trad. de A. López Pina, Madrid, Marcial Pons, 2001, pp. 93, 83-115.
}

Esta obra está bajo una Licencia Creative Commons

Atribución-NoComercial-SinDerivar 4.0 Internacional, IIJ-UNAM.

Boletín Mexicano de Derecho Comparado, núm. 150, pp. 1215-1258 
tiva de la Constitución y su garantía jurisdiccional. En efecto, las Constituciones han incorporado un contenido variopinto de valores, principios o derechos fundamentales con indudable vocación de eficacia. Basta recordar, a este respecto, que durante mucho tiempo las normas constitucionales carecieron de aplicabilidad directa, considerándose como meros programas políticos, a completa disposición del legislador (hecho particularmente cierto en el contexto continental europeo). En el paradigma actual, por el contrario, la Constitución con su contenido material se considera norma jurídica en todo el sentido de la expresión. Los valores nos remiten a la idea del derecho "rematerializado" de nuestros días (en la expresiva idea de M. La Torre), presidida por una Constitución que no sólo reconoce los derechos de los individuos e instituye los poderes del Estado, sino que pretende condicionar la totalidad de las relaciones sociales. ${ }^{7}$

Ese contenido, como hemos dicho, deja de ser "proclama" para tenerse por todos los operadores jurídicos (y en algunos casos también por los particulares) como normas directamente vinculantes, garantizadas por órganos jurisdiccionales especializados. Y éste es precisamente el otro aspecto básico en dicho modelo: el afianzamiento de la justicia constitucional. La consolidación de la garantía jurisdiccional de la Constitución, efectivamente, ha acompañado el reforzamiento del carácter normativo del texto supremo, precisando la creación de métodos interpretativos conformes al objeto interpretado. Ahora bien, la "judicialización" antes aludida supone un reacomodo para la teoría tradicional de la división de poderes en detrimento del legislador y de su capacidad de creación normativa. De ahí

7 La Torre, Massimo, "Derecho y conceptos de derecho. Tendencias evolutivas desde una perspectiva europea", $R C E C$, Madrid, CEC, núm. 16, 1993, p. 71. De la misma forma, es común encontrar entre los rasgos esenciales del constitucionalismo contemporáneo algunas dicotomías. Así, la idea de valor se afirma en lugar de las reglas; la ponderación entre principios que colisionan en lugar de una "mera" subsunción de los mandatos; la omnipresencia de la Constitución en lugar de la independencia del derecho ordinario; la omnipresencia judicial apoyada en la Constitución en lugar de autonomía del legislador. Cfr. Prieto, Luis, Constitucionalismo y positivismo, México, Fontamara, pp. 6-15. Puede verse también Zagrebelsky, Gustavo, El derecho dúctil. Ley, derechos, justicia, 7a. ed., trad. de Marina Gascón, Madrid, Trotta, 2007, p. 21.

8 Dürig, Günter, "Una introducción a la Ley Fundamental de la República Federal de Alemania”, en Karpen, Ulrich, La Constitución de la República Federal de Alemania. Ensayos referentes a los derechos fundamentales y los principios de la Ley Fundamental, Baden-Baden, Nomos, 1992, p. 14. 
que se haga necesario discutir también los límites entre política y derecho: la tensión entre democracia y constitucionalismo; el problema de los límites legítimos a las decisiones de la mayoría o el papel que están llamados a desempeñar los jueces en la salvaguarda de los derechos son problemas que no pueden soslayarse. ${ }^{9}$

Si volvemos nuestra mirada a los ordenamientos jurídicos concretos que han aparecido con posterioridad a la segunda posguerra, encontraremos que los elementos aludidos se han ido integrando en varios países de Occidente. Tomando el caso alemán - pero lo mismo podría decirse del español o italiano- destaca la positivación, en los artículos 1 o. y 19 de la Ley Fundamental de Bonn, de los siguientes dispositivos: la vinculación general de la Constitución, su eficacia directa, el contenido esencial y la tutela judicial. Estos artículos reflejan de forma nítida la manera en que la Ley Fundamental quiere desmarcarse de su antecesora, la Constitución de Weimar, sobre todo en la afirmación del carácter normativo de las disposiciones de derechos fundamentales. Ahora, se dice, éstos vincularán de manera directa a los poderes públicos, sin que estos últimos puedan "vaciarlos" de contenido; es decir, los derechos ya no son "lírica constitucional". ${ }^{10}$ El establecimiento de la cláusula de su contenido esencial se entiende en la medida en que se pretende evitar que el legislador los prive del contenido que los haga reconocibles como tales.

Es en este marco donde los derechos fundamentales adquirieron una función adicional a la de protección de los individuos frente al poder (dimensión subjetiva). Ahora bien, ¿a qué podríamos atribuir este giro? Una respuesta la podemos encontrar en la propia positivación de los derechos, en tenerlos como normas jurídicas en sentido estricto: para que los derechos fundamentales puedan imponer obligaciones o deberes a los poderes públicos, es preciso que los mismos se incorporen en normas. De ahí que

${ }^{9}$ A este respecto sigue siendo muy útil la lectura del clásico texto de Bachof, Otto, Fueces y constitución, trad. de R. Bercovitzs, Madrid, Civitas, 1987; pueden verse también los tres últimos ensayos — autoría de Francisco J. Ansuátegui Roig, Mariano C. Melero de la Torre y Jeremy Waldron, respectivamente - del libro que coordiné: Mora Sifuentes, Francisco M. (coord.), Democracia. Ensayos de filosofia política y jurídica, México, Fontamara-IEEG, 2014, pp. 157 y ss.

10 Alexy, Robert, "Derechos fundamentales y Estado constitucional democrático", trad. de A. García Figueroa, en Carbonell, Miguel (ed.), Neoconstitucionalimo (s), Madrid, Trotta, 2003, p. 33.

Esta obra está bajo una Licencia Creative Commons

Atribución-NoComercial-SinDerivar 4.0 Internacional, IIJ-UNAM.

Boletín Mexicano de Derecho Comparado, núm. 150, pp. 1215-1258 
entre el derecho fundamental y normas de derecho fundamental, tal y como destaca R. Alexy, existan importantes conexiones: "siempre que alguien posee un derecho fundamental, existe una norma válida de derecho fundamental que le otorga este derecho. Por ello, toda aseveración acerca de la existencia de un derecho fundamental tiene como presupuesto la vigencia de una norma de derecho fundamental". ${ }^{11}$

Creo que ahora puede apreciarse de manera más clara a lo que hacía referencia: con esa incorporación al ordenamiento jurídico los derechos adquieren una fisonomía de derecho objetivo, derivada de su positivación en normas jurídicas indubitablemente eficaces, ubicadas en las gradas más altas del sistema. Se convertirán en criterios de ordenación para todo el sistema y, como decisiones básicas, merecedores de protección más allá de que exista o no pretensión individual. Lo anterior ha obligado a replantear varias tesis con las que la teoría del derecho venía trabajando. Por ejemplo, lo reseñado pone en duda la idea de que la validez normativa sea una cuestión puramente formal o procedimental. ${ }^{12}$ La idea de que se alumbra el nacimiento de una "nueva cultura jurídica", superadora del positivismo jurídico, por tanto, no resulta sorprendente. ${ }^{13} \mathrm{Y}$ es que con el contenido material que expresan los derechos fundamentales, con el despliegue de su función objetiva, se hacen más patentes los matices que deben introducirse en nuestra comprensión del derecho.

11 Alexy, Robert, Teoría de los derechos fundamentales, 2a. ed., trad. y estudio preliminar de C. Bernal Pulido, Madrid, CEPC, 2007, p. 114.

12 Sobre como los derechos fundamentales constituyen criterios materiales de validez imprimiendo una dimensión "material o "estática" a los sistemas jurídicos y su necesaria caracterización, por tanto, como sistemas "mixtos" pueden verse: Ansuátegui Roig, Francisco Javier, "Positivismo jurídico y sistemas mixtos", en Ramos Pascua, J. A (ed.), El positivismo jurídico a examen. Estudios en homenaje a fosé Delgado Pinto, Salamanca, Universidad de Salamanca, 2006, pp. 601-622; Cuenca Gómez, Patricia, El sistema jurídico como sistema normativo mixto, prólogo de G. Peces-Barba, Madrid, Dykinson, 2008.

13 Véase, por ejemplo, García Figueroa, Alfonso, "La incidencia de la derrotabilidad de los principios iusfundamentales sobre el concepto de derecho", E̊QP, núm. 3, 2003, pp. 197-227. 


\section{DEREGHOS FUnDAMENTALES "POR TODAS PARTES" Y AL MISMO TIEMPO: SU FUERZA EXPANSIVA}

El primer desarrollo en tener presente de la constitucionalización de los derechos, y en el que se establece de modo claro la idea de asignar una vertiente objetiva a los mismos, es el denominado "efecto de irradiación". Por éste puede entenderse su carácter "expansivo": las normas de derechos fundamentales dejan de ser indiferentes para el resto del ordenamiento. Dicho efecto también ha sido denominado "impregnación". El primero de los términos hace referencia a la Ausstrahlungswirkung, desarrollo de impronta alemana vinculado, en un primer momento, a la proyección de los derechos fundamentales en el tráfico jurídico privado. En el segundo de los casos se habla de una "constitucionalización del Ordenamiento jurídico" que, de entrada, parecería ser una idea más amplia que la primera. En ambas, ese efecto derivaría de su consideración como derecho aplicable y tutelable de su fuerza normativa. Ahora bien, el énfasis radica para el caso alemán en su vinculación con el carácter "valorativo" de los derechos, o dicho de otra manera, la naturaleza material de la Constitución. En el caso italiano - rectius, en la reconstrucción de Riccardo Guastini- ello se deriva del lugar privilegiado que ocupan en el sistema de fuentes. Analicemos cómo ha sido representado dicho efecto expansivo de acuerdo con las doctrinas alemana y la italiana.

\section{El "efecto de irradiación"}

Para la doctrina alemana, los derechos fundamentales pueden caracterizarse, entre otras cosas, por: a) su máximo rango, pues están contenidos en la norma constitucional, en el nivel superior del ordenamiento constitucional; b) su máxima fuerza jurídica al vincular como derecho directamente vigente al Legislativo, al Ejecutivo y al Judicial, y al estar su observancia plenamente controlada por los tribunales hasta culminar en el Tribunal Constitucional de Karlsruhe; c) su máxima importancia de objeto, al decidir las cuestiones básicas de la sociedad — la libertad contractual; garantía de la libertad de opinión, prensa, radio, televisión; libertad religiosa; protección a la vida y a la integridad física, etcétera-; y, finalmente, d) su máximo grado de indeterminación, que se advierte del carácter meramente sucinto,

Esta obra está bajo una Licencia Creative Commons

Atribución-NoComercial-SinDerivar 4.0 Internacional, IIJ-UNAM.

Boletín Mexicano de Derecho Comparado, núm. 150, pp. 1215-1258 
lapidario y vacío del texto constitucional. ${ }^{14}$ La importancia de las normas constitucionales, como puede apreciarse, es tanto jerárquica como de contenido: no sólo es que estén al máximo nivel normativo, sino que también tienen por objeto las cuestiones básicas de la sociedad, acogiendo, por tanto, sus valores fundamentales. Se trata de la dimensión "material" o "axiológica" de la Constitución y de la "fuerza integradora de los derechos fundamentales", ideas que, no debe olvidarse, tienen en la obra de Rudolf Smend un antecedente de primer orden. ${ }^{15}$

En su Verfassung und Verfassungsrecht (1928), dicho autor criticó la concepción positivista del Estado y de la Constitución tanto en la vertiente kelseniana como en la vertiente realista propuesta por Ferdinand Lassalle. Para Smend, ambas concepciones son problemáticas por reduccionistas, pues invitan a tenerle únicamente como norma jurídica y resultado de las relaciones fácticas de poder. Observa que al plantearse en esos términos, la noción de Constitución se deja de lado, además de ser la ordenación jurídica de un Estado, también es "la ordenación de la dinámica vital en la que se desarrolla la vida del Estado, el proceso de integración, cuya finalidad es la perpetua reimplantación de la realidad total del Estado[.] La Constitución es la plasmación legal o normativa de aspectos determinantes de este proceso". ${ }^{16}$ La Constitución no tiende a regular supuestos concretos, sino a abarcar la totalidad del Estado y la del proceso integrador. $\mathrm{Y}$ es esta misma finalidad la que no sólo permite, sino que incluso exige del intérprete constitucional una interpretación "extensiva" y "flexible" que difiere en gran medida de cualquier otra forma de interpretación jurídica. ${ }^{17}$

14 Alexy, Robert, op. cit., nota 10, pp. 33-36.

15 Smend, Rudolf, Verffassung und verfassungsrecht [1928], Berlín, Dunker y Humblot, 1968 (hay trad. cast. de José Ma. Beneyto Pérez, "Constitución y derecho constitucional", en id., Constitución y derecho constitucional, Madrid, CEC, 1985, pp. 37-242. Sobre la figura de Smend, véase Lucas Verdú, Pablo, La lucha contra el positivismo jurídico en la República de Weimar. La teoría constitucional de Smend, Madrid, Tecnos, pp. 18 y ss.; Brage Camanzano, Joaquín, "Rudolf Smend: un constitucionalista lúcido en las repúblicas de Weimar y Bonn", en Smend, R., Ensayos sobre la libertad de expresión, de ciencia y de cátedra como derecho fundamental y sobre el Tribunal Constitucional Federal alemán, trad. de J. Brage Camanzano, México, UNAM, Instituto de Investigaciones Jurídicas, 2005, pp. XI y ss.

16 Smend, Rudolf, op. cit., nota 15, p. 132. Esta caracterización recibió una severa crítica por parte de H. Kelsen. Véase Kelsen, Hans, El Estado como integración: una controversia de principio, trad. y estudio introductorio de J. A. García Amado, Madrid, Tecnos, 1997.

17 Smend, Rudolf, op. cit., nota 15, p. 133.

Esta obra está bajo una Licencia Creative Commons Atribución-NoComercial-SinDerivar 4.0 Internacional, IIJ-UNAM. Boletín Mexicano de Derecho Comparado, núm. 150, pp. 1215-1258 
Sostiene Smend que la Constitución como orden integrador es fruto de la "eficacia integradora de sus valores materiales propios" y entre ellos, de forma destacada, los derechos fundamentales. Es en este punto donde se perfilan con mayor claridad las repercusiones de la obra en la caracterización de los derechos fundamentales como "orden de valores". Advierte que una de las principales consecuencias - cuando no la principal - para el derecho positivo del proceso de integración material es un nuevo paradigma para la interpretación de los derechos fundamentales en el marco de la Constitución. Así, contra la opinión general que ve en ellos, al menos en su contenido clásico, el principio de legalidad rector del actuar de la administración pública, enfatiza que los derechos fundamentales no pertenecen al derecho administrativo ni al derecho especial de policía, ni al derecho privado, etcétera, sino que para Smend forman parte del derecho constitucional. ${ }^{18}$

Señala también que los derechos fundamentales pretenden regular, por una parte, una serie material autónoma; es decir, un sistema de valores, de bienes, un sistema cultural y por la otra, lo regula el sistema nacional, como sistema para todos los alemanes, el cual afirma el carácter nacional de esos valores. Desde el punto de vista del derecho especial técnico, para Smend, los derechos fundamentales pueden afectar al legislador, a ciertos departamentos de la administración, a cada individuo, a todos ellos en su conjunto, al igual que a ninguno de ellos. Incluso en el caso de que no reciban su validez directamente, exigen al menos para ser interpretados por el derecho especial, una fundamentación a partir del sistema cultural del que se desprenden. $\mathrm{Al}$ menos en este sentido, los derechos fundamentales representan la "norma que rige a la Constitución, la legislación y la Administración". ${ }^{19}$ Además de la significación mediata o inmediata que pueden tener los derechos fundamentales para el derecho especial técnico, existe otra más —afirma Smend-, que es la fuente de aquélla: los derechos fundamentales son los representantes de un sistema de valores concreto, de un sistema cultural que resume el sentido de la vida estatal contenido en la Constitución. Desde el punto de vista político, esto significa una voluntad de integración material; desde el punto de vista jurídico, la legitimación del orden positivo estatal y jurídico. Este orden positivo es

18 Ibidem, p. 230.

19 Ibidem, p. 231 (cursivas mías).

Esta obra está bajo una Licencia Creative Commons

Atribución-NoComercial-SinDerivar 4.0 Internacional, IIJ-UNAM.

Boletín Mexicano de Derecho Comparado, núm. 150, pp. 1215-1258 
válido sólo en cuanto que representa este sistema de valores y precisamente por él, se convierte en legítimo. ${ }^{20}$

Pues bien, la mayoría de esas notas estarán presentes en el fallo del caso Lüth, en el que el Tribunal Constitucional Federal alemán abordó, en una de sus sentencias más trascendentes que se recuerden, ${ }^{21}$ la mayoría de los temas de los que nos ocuparemos. Si bien lo que subyace en el fondo de la disputa originaria es la posible vigencia de los derechos fundamentales en las relaciones entre particulares, el intérprete constitucional fue más allá, creando figuras y parámetros interpretativos que pretenden dar contenido e integrar los desarrollos dogmáticos que estamos comentando. En la sentencia señaló lo siguiente:

Los derechos fundamentales son, en primer lugar, derechos de defensa del ciudadano frente al Estado. De ahí que la acción de amparo solo proceda contra actos del poder público.

La Constitución, sin embargo, no es neutral respecto de los valores. Los derechos fundamentales traducen un orden o sistema de valores, sustentado en el libre desarrollo de la personalidad y en la dignidad de la persona humana, que en su condición de decisión constitucional básica, está llamada a regir todos los ámbitos del derecho y a ser acatada por todos los órganos del poder. En este sentido, el sistema de valores prohijado por la Constitución, influye en el derecho civil, no pudiendo sus disposiciones contradecirlo y, por el contrario, debiendo ellas interpretarse con arreglo a su espíritu.

$\mathrm{El}$ alcance, efecto e influencia de los derechos fundamentales en el ámbito del Derecho civil, se realiza a través de preceptos propios de esta rama del derecho y, especialmente, de las disposiciones imperativas generales que remiten a conceptos jurídicos indeterminados, los cuales deben ser aplicados e interpretados con estricta sujeción a los primeros. La controversia, aunque su resolución se inspire en principios rectores de la Constitución, sigue siendo de carácter civil y se gobierna por este mismo tipo de reglas.

Si el juez civil deja de reparar en el efecto objetivo que las normas constitucionales relativas a los derechos fundamentales producen sobre las disposiciones del Derecho civil —efecto de irradiación - viola con ocasión de su

20 Idem.

21 A la misma se ha llegado a calificar como una de las bases del actual sistema jurídico-constitucional alemán. Véase Henne, Thomas y Riedlinger, Arne (eds.), Das Lüth-Urteil aus (rechts-) historischer Sicht Die Konflikte um Veit Harlan und die Grundrechtsjudikatur des Bundesverfassungsgerichts, Berliner Wissenchafts-Verlag, 2005.

Esta obra está bajo una Licencia Creative Commons Atribución-NoComercial-SinDerivar 4.0 Internacional, IIJ-UNAM. Boletín Mexicano de Derecho Comparado, núm. 150, pp. 1215-1258 
fallo el derecho fundamental que ha debido proteger y cuya observancia judicial le es impuesta, como quiera que a ello el titular tiene derecho. En este caso, contra las sentencias lesivas de los derechos fundamentales, sin perjuicio de los restantes recursos, cabe la acción de amparo ante el Tribunal Constitucional Federal, el cual limitará su examen a la cuestión constitucional únicamente, vale decir, al análisis aludido - efecto de irradiación - y a su correcta o incorrecta valoración por parte del juez de la causa. ${ }^{22}$

Estimo que la transcripción completa de estos párrafos se justifica en la medida en que en ellos queda plasmada la potencia asignada por el máximo intérprete de los derechos fundamentales y, sobre todo, la importancia que adquirieron para el orden democrático de convivencia consagrado en la Ley Fundamental; es decir, su llamamiento a "regir en todos los ámbitos del derecho". Con ella los derechos inauguran su imparable ascenso y propagación. R. Alexy, por su parte, estima que el sistema de valores establecido en la Constitución puede explicarse a través de su estructura normativa de principios: "al convertirse en principios o valores pueden aparecer por todas partes, pueden ser relevantes en cualquier asunto jurídico. Esta circunstancia explica la ubicuidad de los derechos fundamentales, idea que en su esencia logra describirse mediante el concepto de expansión en todas las áreas del Derecho"; ${ }^{23}$ sin embargo, las anteriores afirmaciones requieren puntualizarse.

Es de sobra conocido que Alexy racionaliza la jurisprudencia del Tribunal Federal Constitucional alemán - aunque su teoría tiene, por su carácter analítico, un alcance general- . Ahora bien, como pudo advertir el lector, el profesor de Kiel ha reconducido la doctrina del "orden objetivo de valores" (Objektive Wertordnung) del fallo Lüth por su "teoría de los principios". Entre las razones que él mismo esgrime destacan dos: la primera sostiene que el concepto de "valor" resulta más comprometido tanto filosófica como políticamente, y la segunda es porque los valores no tienen

22 Esta traducción del fallo Lüth la encontramos en Cifuentes Muñoz, Eduardo, La eficacia de los derechos fundamentales frente a particulares, UNAM, Instituto de Investigaciones Jurídicas, 1998, p. 13 (cursivas añadidas).

23 Alexy, Robert, "Derecho constitucional y derecho ordinario-jurisdicción constitucional y jurisdicción ordinaria", en $i d$., Tres escritos sobre los derechos fundamentales y la teoría de los principios, trad. C. Bernal Pulido, Bogotá, Universidad Externado de Colombia, 2003, pp. 41-92.

Esta obra está bajo una Licencia Creative Commons

Atribución-NoComercial-SinDerivar 4.0 Internacional, IIJ-UNAM.

Boletín Mexicano de Derecho Comparado, núm. 150, pp. 1215-1258 
naturaleza "deontológica" que sí tendrían los "principios". ${ }^{24}$ Desde mi punto de vista, esto es algo que debe destacarse: su teoría de los principios se ha ido abriendo paso al grado de que, prácticamente, ha sustituido a la teoría de los valores con la que inició la dimensión objetiva. Las normas de derechos, en tanto "mandatos de optimización", ${ }^{25}$ son según él, la base para poder comprender su carácter "holístico" y "comprehensivo"; ${ }^{26}$ son, podríamos decir, la llave de la ciencia contemporánea de los derechos, cuya fecundidad se aprecia en la práctica de los tribunales a nivel nacional e internacional. El profesor de Kiel explica, desarrolla y problematiza todo su sistema con base en su distinción entre principios y reglas.

\section{La "constitucionalización del ordenamiento jurídico"}

La fuerza expansiva de los contenidos constitucionales puede ejemplificarse en sentido similar con la idea de "constitucionalización del ordenamiento jurídico". En un trabajo muy influyente, R. Guastini ha identifica-

24 Alexy, Robert, op. cit., nota 11, pp. 117 y ss.

25 Como se sabe, el concepto de "principio" ha dado lugar a discusiones prolijas en los últimos años. Básicamente hay dos posturas, una distinción fuerte (ontológica) y una débil (de grado) entre principios y reglas. La teoría de Alexy (principios como "mandatos de optimización") y la de Ronald Dworkin (principios como "triunfos") pertenecen a la distinción fuerte - que dicho sea de paso ha sido utilizada para socavar la tesis positivista de la separación conceptual entre derecho y moral- Con todo, entre ellas también existen diferencias muy importantes, destacándose que Alexy no distingue entre "principles" y "policies" como sí hace Dworkin (véase Alexy, Robert, "Die Konstruktion von Grundrechte", en Clérico, L. y Sieckmann, J.R (eds.), Grundrechte, Prinzipien und Argumentation. Studien zur Rechtstheorie Robert Alexys, Nomos, Baden-Baden, 2009). Ello ha sido objeto de fuertes críticas. Habermas, por ejemplo, ha sostenido que, así entendidos, los principios (derechos) pierden su naturaleza deontológica, algo que, evidentemente, niega Alexy. (Véase La Torre, Massimo, "Nueve críticas a la teoría de los derechos fundamentales de Alexy", en Menéndez, A. J. y Eriksen, E. O. (eds.), La argumentación y los derechos fundamentales, trad. de C. Bernal Pulido, Madrid, CEPC, 2010). Extenderme en este punto me llevaría demasiado lejos y, teniendo en cuenta las finalidades de este trabajo, estimo, no es necesario profundizar más. Me he ocupado de las diferencias, similitudes y problemática de los principios en tanto "mandatos de optimización" de Alexy con otras teorías principialistas en mi disertación doctoral. Véase Mora Sifuentes, Francisco M., Legalismo y constitucionalismo. Pautas para una reconstrucción del imperio de la ley de la Constitución, Universidad Carlos III de Madrid-Instituto de Derechos Humanos "Bartolomé de las Casas", 2014, cap. IV.

26 Alexy, Robert, "Derechos fundamentales, ponderación y racionalidad", trad. de R. Sánchez, RIDPC, núm. 11, 2009, pp. 3-14. 
do diversas condiciones para la misma. Tal idea consiste, básicamente, en la "impregnación" de todo el derecho de contenidos constitucionales. Así, para el profesor italiano se trata de un proceso que supone la transformación de un ordenamiento, al término del cual el ordenamiento en cuestión resulta totalmente impregnado por las normas constitucionales: "un ordenamiento jurídico constitucionalizado se caracteriza por una Constitución extremadamente invasora, entrometida, capaz de condicionar tanto la legislación como la jurisprudencia y el estilo doctrinal, la acción de los actores políticos así como las relaciones sociales". ${ }^{27}$ Obsérvese que, como todo proceso, la constitucionalización puede darse conforme cada ordenamiento reúna algunas características, por lo que no se puede hablar de ella como una categoría de "todo o nada". Más bien, habría que analizarla en cada caso concreto. De esta forma, algunos ordenamientos estarían más "constitucionalizados" que otros, dependiendo del grado en que se pueda advertir el influjo de los contenidos constitucionales.

Tomando como caso el ordenamiento jurídico italiano, Guastini va a identificar diversas condiciones para poder hablar de un "ordenamiento constitucionalizado". Las condiciones que se precisan, a su juicio, son las siguientes:

1. Rigidez constitucional.

2. Garantía jurisdiccional de la Constitución.

3. Fuerza vinculante de la Constitución.

4. Sobreinterpretación de la Constitución.

5. Interpretación conforme de las leyes.

6. Aplicación directa de la Constitución a cargo de los jueces ordinarios.

7. Influencia de la Constitución sobre las relaciones políticas. ${ }^{28}$

Ahora bien, entre ellas, sostiene que sólo la primera condición (rigidez constitucional) y la segunda (garantía jurisdiccional de la Constitución) son necesarias; esto es, su presencia es condición sine qua non para que la constitucionalización de un ordenamiento pueda realizarse. Menciona,

27 Guastini, Riccardo, "La constitucionalización del ordenamiento jurídico italiano", trad. de Alonso Lujambio, en Carbonell, M. (ed.), Neoconstitucionalismo(s)..., cit., pp. 49-74; también en Guastini, Riccardo, Estudios de teoría constitucional, trad. de M. Carbonell, México, Fontamara-UNAM-Instituto de Investigaciones Jurídicas, 2001, p. 153.

28 Guastini, Riccardo, "La constitucionalización del...", cit., pp. 49 y ss.

Esta obra está bajo una Licencia Creative Commons

Atribución-NoComercial-SinDerivar 4.0 Internacional, IIJ-UNAM.

Boletín Mexicano de Derecho Comparado, núm. 150, pp. 1215-1258 
asimismo, que existen conexiones importantes entre las condiciones tercera, cuarta y quinta, señaladas. ${ }^{29}$ Repasemos brevemente cada una de ellas.

La rigidez constitucional radica en el carácter escrito del texto constitucional y su separación jerárquica de la legislación ordinaria. Las normas constitucionales no pueden derogarse o modificarse si no es mediante un procedimiento especial de revisión constitucional (más complejo que el procedimiento de formación y reforma de las leyes ordinarias). La jerarquía se manifiesta, sobre todo, en la idea de que la Constitución está por encima de la legislación ordinaria, y las normas inferiores no pueden contradecirla. Por último, destaca Guastini que ese proceso se hace más notorio donde existen cláusulas constitucionales que no son susceptibles de reforma (las así llamadas "cláusulas pétreas"); ni siquiera a través del procedimiento de reforma constitucional. La garantía jurisdiccional de la Constitución, por su parte, es, a su vez, indispensable para asegurar la rigidez y jerarquía de la norma básica: donde no esté establecida la justicia constitucional, en cualesquiera de sus variantes o modelos, difícilmente estará asegurada la regularidad constitucional.

La fuerza vinculante de la Constitución es para Guastini una ideología difundida en la cultura jurídica y no un dato que tenga que ver con la estructura del ordenamiento. Así, contra la postura de que las normas constitucionales no son sino meros programas políticos a desarrollar por el legislador, la ideología actual radica en la creencia de que "toda norma constitucional - independientemente de su estructura o contenido normativo - es una norma jurídica genuina, vinculante y susceptible de producir efectos jurídicos". ${ }^{30}$ Por otra parte, la sobreinterpretación de la Constitución radica, de igual forma, en la adopción de un tipo "extensivo" de interpretación constitucional, lo que da como resultado que no queden espacios libres o vacíos de derecho constitucional de tal forma que "toda decisión legislativa está prerregulada (quizá minuciosamente regulada) por una o por otra norma constitucional. No existe ley que pueda escapar al control de legitimidad constitucional", ${ }^{31}$ no hay espacio para la discrecionalidad legislativa. Por otra parte, la aplicación directa de la Constitución supone la difusión de una cierta concepción de la Constitución y de la

29 Ibidem, p. 50.

30 Ibidem, p. 53.

31 Ibidem, pp. 53 y 54.

Esta obra está bajo una Licencia Creative Commons Atribución-NoComercial-SinDerivar 4.0 Internacional, IIJ-UNAM. Boletín Mexicano de Derecho Comparado, núm. 150, pp. 1215-1258 
adopción de una actitud de los jueces. Esa concepción radica en afirmar que la Constitución moldea también las relaciones sociales - estrechando el límite entre Estado y sociedad - y que debe aplicarse de manera directa por cualquier juez con motivo de cualquier controversia jurídica.

La interpretación conforme de las leyes radica en la asunción interpretativa de los jueces, por la cual interpretan las disposiciones legales de tal forma que se evite una lectura inconstitucional de las mismas. Esto es, entre dos interpretaciones posibles de una norma en donde una dé como resultado que la misma es contraria a la Constitución y otra donde, a la inversa, sea coherente, los jueces prefieren esta última a fin de armonizarlas: "interpretación conforme es aquella que adecua la ley con la Constitución, eligiendo el significado que evite toda contradicción entre la ley y la Constitución". ${ }^{32}$ La última condición, la influencia de la Constitución en las relaciones políticas, es la más difícil de precisar. Según Guastini, ella depende del contenido mismo de la Constitución, la postura de los jueces, de los órganos constitucionales y de los actores políticos. Es decir, tiene que ver, por una parte, con las competencias atribuidas al Tribunal Constitucional respecto a cuestiones de indudable contenido político; con la actitud de deferencia o no de los jueces sobre esas cuestiones - activismo judicial vs. self-restraint-, y, por último, con el grado en que los actores políticos argumentan o utilizan la Constitución para justificar sus acciones y decisiones. ${ }^{33}$ Hasta aquí la exposición del profesor de Génova.

Si se observa con atención, son muy parecidos los requisitos que según ambos teóricos se precisan para que en un determinado ordenamiento jurídico pueda desarrollarse el "efecto de irradiación" o la "impregnación" de los contenidos constitucionales a todos los ámbitos del derecho. En ambos casos se trata de ejemplos que se desenvuelven dentro del constitucionalismo contemporáneo aludido. Ahora bien, por lo que respecta al concepto de "irradiación", y aunque pareciera que el mismo se circunscribe a la idea de la vigencia de los derechos en las relaciones entre particulares (Drittwirkung der Grundrechte), considero que el mismo puede extender su ámbito explicativo sin mayores problemas y utilizarse como sinónimo de “impregnación”. En ambos casos la idea será, como advirtió el profesor italiano, una Constitución invasora que pretende condicionar la totalidad

\footnotetext{
32 Ibidem, p. 56.
}

33 Ibidem, p. 57.

Esta obra está bajo una Licencia Creative Commons

Atribución-NoComercial-SinDerivar 4.0 Internacional, IIJ-UNAM.

Boletín Mexicano de Derecho Comparado, núm. 150, pp. 1215-1258 
de las relaciones políticas y sociales. El matiz, desde mi punto de vista, radica en el énfasis que se coloca en el carácter valorativo o de "principios" de los derechos en el caso alemán y su consideración como derecho positivo y vinculante en el caso de Guastini - que, adviértase, no incide en el carácter valorativo del fenómeno- - En definitiva, el efecto puede atribuirse al trasfondo moral del derecho fundamental, a su estructura de "principio" o la posición que ocupan en el ordenamiento. Ello depende de las preferencias conceptuales del autor.

Lo importante, en todo caso, es que desde el punto de vista de una teoría jurídica, los derechos fundamentales se convierten en criterios de validez. Esto quiere decir que los poderes públicos - y los privados con algunos matices-, no pueden desentenderse de los mismos: deberán respetar y tener en cuenta en sus actuaciones todo el sistema de derechos fundamentales establecido en la Constitución. En caso contrario, sus actos no pueden reputarse como válidos por los órganos encargados de su garantía. Sin embargo, esta forma de comprender la dimensión objetiva no alcanza a cubrir otro aspecto básico derivado de ella, consistente en que los mismos imprimen "directrices" o "deberes" de protección a los poderes constituidos. Y es aquí donde se hace necesario ampliar la base liberal del sistema constitucional de derechos. ${ }^{34}$

\section{DEBERES DE PROTEGGiÓN A GARGO DEL ESTADO}

Derivado de la atribución del carácter objetivo a los derechos fundamentales, surge también la figura de los "deberes", "mandatos" u "obligaciones de protección" (Schutzpflichten). Ésta se refiere genéricamente a la conducta que los poderes públicos están llamados a realizar para que los derechos o bienes iusfundamentales se realicen efectivamente o se protejan. El Estado, se ha dicho, "tiene la obligación positiva de contribuir a la efectividad de los derechos, aun cuando no exista una pretensión subjetiva por parte del ciudadano". ${ }^{35}$ De tal forma que además de su función garan-

34 Sobre este punto en particular, permítaseme una referencia a un trabajo de mi autoría que, en gran medida, es complementario del presente, véase Mora Sifuentes, Francisco M., "Ideas de libertad y modelos de derechos fundamentales. Una aproximación", Cuestiones Constitucionales. Revista Mexicana de Derecho Constitucional, núm. 28, 2013, pp. 171-210.

35 Fernández Segado, Francisco, "La teoría jurídica de los derechos fundamentales en la doctrina constitucional", REDC, núm. 19, 1993, p. 210.

Esta obra está bajo una Licencia Creative Commons Atribución-NoComercial-SinDerivar 4.0 Internacional, IIJ-UNAM. Boletín Mexicano de Derecho Comparado, núm. 150, pp. 1215-1258 
tizadora de protección del individuo frente al poder estatal, se le suman las correspondientes obligaciones de seguridad y de protección por parte del Estado, "en forma de deberes y mandatos protectores de los poderes públicos y, en especial, del legislador". ${ }^{36}$ Las distintas "transformaciones" ${ }_{37}$ que ha sufrido el Estado contemporáneo resultan importantísimas para comprender las funciones de promoción y protección aludidas. La idea de tránsito del Estado liberal al que se ha denominado Estado social y democrático de derecho puede resultar esclarecedora.

\section{Transformaciones del Estado y deberes de protección}

Se recordará que el Estado liberal es aquel que surge de la mano de las revoluciones burguesas en respuesta a la cada vez más insoportable situación imperante del Ancien Régime. La Revolución francesa, como ha escrito Elías Díaz, marca el fin del régimen absolutista, y el comienzo e instauración de los regímenes liberales significa el paso de una sociedad estamental a una sociedad clasista, siendo la primera manifestación "de lo que después se llamaría Estado de Derecho". ${ }^{38}$ Este momento representó un avance muy notable a fin de organizar jurídicamente a la sociedad, pero sobre todo respecto de los límites del poder absoluto. El Estado - en sus primeras formulaciones - fue, ante todo, un garante de posiciones liberales, era, o aparentaba ser, un Estado abstencionista. ${ }^{39}$

Fue en su posterior evolución, hacia un Estado social y democrático de derecho, cuando comienza a advertirse con más notoriedad que los

36 Stern, Klaus, "Sistema de derechos fundamentales en la República Federal de Alemania”, RCEC, núm. 1, 1988, p. 136.

37 La idea de "transformaciones del Estado" la tomo del título del libro de García Pelayo, Manuel, Las transformaciones del Estado contemporáneo, Madrid, Alianza, 1977. Podría pensarse que no es el Estado el que se transforma, sino las concepciones (o la ideología política) que le sustenta. Pero, desde mi punto de vista, ello es dudoso: el Estado que se aboca a la satisfacción de necesidades materiales - el Estado social - precisa de un aparato mucho más sofisticado para suministrar aquello que los ciudadanos no pueden obtener por sí en el mercado. Es decir, se transforma en su configuración y funcionamiento. No por nada la crítica neoliberal (Hayek, Friedman, etcétera) ve en esta concepción más amplia no sólo un Estado "obeso" o "paternalista", sino la ruta hacia un "camino de servidumbre".

38 Díaz, Elías, Estado de derecho y sociedad democrática, 9a. ed., Madrid, Taurus, 1998, pp. 39 y 40 .

39 Díaz, Elías, "Estado de derecho: exigencias internas, dimensiones sociales", Sistema, núm. 125, 1995, pp. 13 y 14.

Esta obra está bajo una Licencia Creative Commons

Atribución-NoComercial-SinDerivar 4.0 Internacional, IIJ-UNAM.

Boletín Mexicano de Derecho Comparado, núm. 150, pp. 1215-1258 
poderes públicos asumen un papel más activo para que los presupuestos igualitarios sobre los que descansa intenten hacerse efectivos. Es decir, el Estado va a modular, corregir, en alguna medida, las relaciones sociales. De ahí que el Estado social de derecho se conciba como "una fórmula que - a través de una revisión y reajuste del sistema- evite los defectos del Estado abstencionista liberal y sobre todo, del individualismo que le servía de base postulando planteamientos de carácter social"..$^{40}$ A su vez, dichos planteamientos pueden diferenciarse de cualquier sistema cercano a los totalitarismos, sea éste de cualquier signo.

Es interesante cómo E. Forsthoff, notable crítico de la concepción valorativa de los derechos, describe la forma en que se fue operando dicho cambio y se imprimieron los mencionados deberes de protección. Según este autor, en su clásico El Estado social en la sociedad industrial, para atribuir a los derechos una función social era necesario prescindir del modo de entenderlos hasta entonces imperante: como limitación del Estado, como protección jurídica del individuo frente a las intervenciones estatales. Esto era necesario, pues la concepción negativa de los derechos no ofrecía en la práctica ningún puente lógico para su interpretación social ni la ofrecía la ansiada posibilidad de hermanar Estado de derecho y Estado social sobre la base común de los derechos fundamentales. De esta manera, se precisaba transformar en positivos unos derechos que se habían formulado a la defensiva y, por ello, negativamente. De ahí que, para hacer compatible la acción estatal con los derechos - continúa este autor-, fue necesario que éstos se entendieran como principios positivos. Ello fue posible a través de concebir los derechos como la positivación de valores y la totalidad de derechos fundamentales como sistema de valores inherentes a la Constitución. ${ }^{41}$

Téngase en cuenta que para Forsthoff, la posibilidad de hacer compatibles las exigencias del Estado liberal, tal y como fue concebido, con las del Estado social, eran del todo equivocadas, ya que en su sentido intencional cada uno es completamente diverso, por no decir antagónico. El Estado de derecho tiene sus propias instituciones, formas y conceptos referidos a la libertad. El Estado social, consecuente en su realización prác-

40 Díaz, Elías, op. cit., nota 37, p. 101. Utilizo en esta parte como sinónimos "Estado social" y "Estado social y democrático de derecho", aunque, en estricto sentido, no lo sean. Lo hago por simplificar mi exposición.

41 Forsthoff, Ernst, El Estado de la sociedad industrial, trad. de L. López Guerra y J. Nicolás Muñiz, Madrid, Instituto de Estudios Políticos, 1975, p. 252. 
tica, establece también sus propias instituciones, formas y nociones que han de estar configuradas de modo sustancialmente distinto. ${ }^{42}$ Forsthoff pensaba sobre todo en las cargas que el Estado social imprime al modelo político-jurídico; particularmente, a través de los denominados derechos sociales, los cuales no son sino "conceptos bien intencionados, moralmente encomiables, pero jurídicamente en las nubes, de los que no faltan suficientes en la Ley Fundamental, no sólo no amplían la protección de los derechos fundamentales, sino que son perjudiciales porque les hacen perder seguridad". ${ }^{43}$

De ser así, ¿deberíamos entender que el Estado de derecho como tal tiene asignada una función originaria - exclusiva y excluyente- - que no le permitiría abocarse a la consecución de los fines que el derecho en el marco del Estado social y democrático se plantea? Esta cuestión no debe dejarse de lado. Si es cierto, como ha sido planteado, que existe un tipo de conexión conceptual entre Estado de derecho y los derechos fundamentales, es decir, que siempre que se hable de aquél resulta un requisito indispensable el respeto a los derechos humanos, ${ }^{44}$ la respuesta creo debe ser matizada en dos sentidos. El problema gira en torno a los requisitos que debe cumplir una determinada organización jurídico-política para recibir hoy en día el prestigioso membrete de "Estado de derecho" o si se quiere, de forma más elemental, qué tipo de derechos ha de garantizar para tal fin.

42 Forsthoff, Ernst, "Concepto y esencia del Estado social de derecho", en Abendroth, Wolfgan et al., El Estado social, Madrid, CEC, 1986, pp. 71-106, aquí p. 86. Según Forsthoff (idem), los cambios que han operado pueden verse de forma más clara en la realización de las garantías jurídico-sociales: "estas no consisten primariamente en limitaciones, sino en participación. Libertad y participación son nociones cardinales que configuran hoy las relaciones del individuo con el Estado, que son entre sí muy diversas y contrarias. La libertad garantizada mediante una limitación hace referencia a un Estado que se traza límites a sí mismo, deja pues al individuo en la situación social que tiene; por consiguiente, también al Estado que, en esa relación de libertad, mantiene el status quo. La participación como derecho y pretensión supone un Estado que ayuda, reparte, distribuye y adjudica, que no abandona al individuo en su situación social sino que acude en su ayuda mediante subsidios. Tal es el Estado social”. (El énfasis es mío).

43 Forsthoff, Ernst, op. cit., nota 40, p. 258.

44 Ansuátegui Roig, Francisco Javier, "Las definiciones del Estado de derecho y los derechos fundamentales", Sistema, núm. 158, 2000, p. 102.

Esta obra está bajo una Licencia Creative Commons

Atribución-NoComercial-SinDerivar 4.0 Internacional, IIJ-UNAM.

Boletín Mexicano de Derecho Comparado, núm. 150, pp. 1215-1258 
Parece que la discusión está dominada por dos extremos: para que fuera posible hablar de Estado de derecho, en la actualidad, se haría necesario el respeto y garantía de las distintas generaciones de derechos, en lo particular la garantía de los denominados derechos sociales - derechos económicos, sociales y culturales (DESG) - ; o bien para hablar de Estado de derecho basta con la garantía de los derechos civiles y políticos. Esta parece ser la perspectiva de Forsthoff: valdría únicamente con que se respetaran los derechos postulados por el Estado de derecho liberal decimonónico, e inclusive habría que prescindir de los denominados derechos sociales si queremos que la garantía de los derechos civiles y políticos sea efectiva.

Aquí sostenemos que la atribución de una vertiente objetiva a los derechos fundamentales encuentra un mejor marco de análisis y fundamentación en un modelo amplio de Estado de derecho. Resulta muy complicado dar cuenta de las consecuencias de asignar una vertiente objetiva a la luz de los desarrollos de la actual teoría de los derechos fundamentales, si anclamos su concepción en un modelo liberal o restringido. Aún más, en la mayoría de los casos, quienes sostienen o parten de una visión liberal de la sociedad y de las instituciones políticas, rechazan asignar una vertiente objetiva a los derechos..$^{45} \mathrm{Y}$ la rechazan precisamente por considerarla totalmente incompatible con los presupuestos en los que descansa la propia concepción liberal de los derechos, de las categorías jurídicas acuñadas en ella; pero sobre todo, por el temor de que su "propia identidad" 46 se pierda.

45 Ejemplo de autores que sostendrían este punto de vista serían Forsthoff, ya mencionado, o el propio E. -W. Böckenforde. De este último véase, "Teoría e interpretación de los derechos fundamentales", en id., Escritos sobre derechos fundamentales, trad. J. L. Requejo e I. Villaverde, Madrid, Trotta, 1993, pp. 69 y ss.

46 Hesse, Konrad, Derecho constitucional y derecho privado, trad. de I. Gutiérrez, Madrid, Civitas, 1995, pp. 59-62. Ahora bien, ¿ello significa que niegue cualquier virtualidad a estos modelos "estrictos" o "restringidos" de Estado de derecho o de derechos fundamentales? En ningún caso. Ello nos pone de manifiesto que la forma en que se va a entender la función de los derechos en el punto de vista interno es reflejo o estará condicionada por una previa toma de postura. Esa toma de postura se refiere a lo que entendamos por los distintos valores que suponemos están detrás de ellos, desde lo que se ha denominado aquí "punto de vista externo". Se trata, nuevamente, de las diferentes posiciones sobre la naturaleza del Estado, las tareas que debe desempeñar, los derechos fundamentales incluidos en la Constitución y de la percepción o visión que se tenga del conjunto de la sociedad. 


\section{Deberes de protección, derechos prestacionales y dimensión objetiva}

Volviendo al tema de los deberes de protección, quiero llamar la atención sobre su interacción con la vertiente objetiva. Se insiste en que la vertiente objetiva implica que los poderes públicos tienen obligaciones de actuación para la efectiva realización y goce de los derechos fundamentales. Ese deber de actuación positiva, por un lado, se suele vincular con el marco de actuación que tienen los poderes con respecto a los derechos menos resistentes o de garantía disminuida - léase aquí "derechos sociales" - y, por el otro, suele considerarse como algo excluido de la dimensión subjetiva. Esto es correcto en alguna medida.

Sin embargo, no es del todo exacto. Y no lo es, si se contrasta con la definición que hemos realizado aquí de la función objetiva, es decir, de la desvinculación por parte de su titular. De entrada, el deber de actuación positiva del Estado no puede equipararse sin más con la vertiente objetiva, puesto que dicho deber de actuación le está impuesto al poder público en ambas dimensiones; esto es, tanto para la dimensión objetiva como para la subjetiva. Como puede observarse, esto ayuda a relativizar la afirmación según la cual existen derechos que para su satisfacción impliquen acciones o abstenciones. ${ }^{47}$ Ello nos pone de manifiesto que el deber de protección es más amplio y que, por tanto, deben tenerse en cuenta sus gradaciones.

Lo anterior puede apreciarse de forma más clara si tomamos la exposición de R. Alexy respecto a los derechos prestacionales. Entiende Alexy que todo derecho a una acción positiva del Estado, es un derecho prestacional. De esta manera, el derecho prestacional es la contrapartida - lo opuesto - del concepto de derecho de defensa, bajo el que cae todo derecho a una acción negativa: a una omisión por parte del Estado o de otro sujeto. La escala de las acciones positivas del Estado que pueden ser ob-

47 Muchos estudios cuestionan las supuestas "diferencias de naturaleza" que existirían entre los derechos civiles y políticos, por un lado, y los derechos sociales, por el otro. Una de las más acusadas vendría a ser precisamente esta, la idea según la cual existen derechos que únicamente imponen deberes de abstención y otros derechos que imponen exclusivamente deberes de actuación. Véanse Fabre, Cécile, Social Rights Under the Constitution. Goverment and the Decent Life, Oxford, OUP, 2004, pp. 40 y ss.; Ansuátegui Roig, Francisco Javier, "Argumentos para una teoría de los derechos sociales", Revista Derecho del Estado, núm. 24, 2010, pp. 45-64.

Esta obra está bajo una Licencia Creative Commons

Atribución-NoComercial-SinDerivar 4.0 Internacional, IIJ-UNAM.

Boletín Mexicano de Derecho Comparado, núm. 150, pp. 1215-1258 
jeto de un derecho prestacional abarca desde la protección del ciudadano frente a otros ciudadanos a través de normas de derecho penal, pasando por la creación de normas de organización y procedimiento, y llega hasta prestaciones en dinero y en bienes. ${ }^{48}$ Aquí me interesa resaltar que el deber de protección puede entenderse, en una primera instancia, en ese sentido amplio, en la cual incluya tanto prestaciones fácticas como normativas tales como la protección por medio de normas de derecho penal o la creación de normas de organización y procedimiento. ${ }^{49}$

Según Alexy, dos son los motivos que aconsejarían adoptar esta definición amplia de derechos prestacionales en la que se incluyan las que él denomina prestaciones "fácticas" y "normativas". El primer motivo tiene que ver con la amplia o abstracta formulación que muchos de los derechos sociales fundamentales presentan y por lo cual comprenden, a su vez, una serie de derechos y obligaciones, competencias, poderes e inmunidades. De ahí que diga que este tipo de derechos y las prestaciones que su cumplimiento exigen no comprendan única y exclusivamente prestaciones de dar o proporcionar recursos; esto es, que se trata de derechos a prestaciones fácticas sí, pero sólo en parte, puesto que también incluyen derechos a prestaciones normativas. El segundo sería que los derechos a acciones positivas imponen al Estado la persecución de determinados fines, objetivos o estados de cosas; a diferencia de los derechos a acciones negativas que le imponen límites al Estado en la persecución de sus fines. Por ello, en relación con los derechos a acciones positivas del Estado se plantea el problema de saber si, y en qué medida, ciertos derechos subjetivos constitucionales de los ciudadanos pueden y deben imponer al Estado la obligación de perseguir ciertos fines. Los derechos prestacionales en sentido amplio pueden dividirse en tres grupos: derechos de protección, derechos a la organización y al procedimiento, y derechos prestacionales en sentido estricto.

Los derechos prestacionales en sentido amplio, nos dice el profesor alemán, presentan la dificultad de determinar en qué medida, y si es posible, pueden adscribírseles derechos subjetivos constitucionales. Es decir, los derechos prestacionales en sentido amplio o se refieren exclusivamente a normas que garantizan derechos subjetivos o bien a normas que no los garantizan. Explica Alexy que si entendemos que los derechos subjetivos

48 Alexy, Robert, op. cit., nota 11, p. 391.

49 Ibidem, p. 393. 
son relaciones entre sujetos jurídicos (si $a$ tiene frente al Estado un derecho a que éste procure protección, organización o procedimiento, entonces el Estado tiene el deber de procurar una determinada protección, organización o procedimiento), todo derecho subjetivo implica, entonces, un deber no relacional, y, en este sentido, un deber objetivo. Lo contrario no es válido. De que el Estado tenga un deber, no se sigue que haya un sujeto jurídico frente al cual exista este deber. De esta forma, la pregunta central respecto a la dicotomía subjetivo/objetivo puede formularse de la siguiente manera: ¿hasta qué punto una protección, organización o procedimiento ordenado por los derechos fundamentales está exigida por normas que confieren derechos subjetivos, y hasta qué punto lo está por normas que sólo fundamentan deberes objetivos, al Estado? ${ }^{50}$

Pongamos como caso el de los derechos de protección. Señala Alexy:

...por derechos de protección se entienden los derechos del titular del derecho fundamental frente al Estado para que éste lo proteja de intervenciones de terceros. Su espectro se extiende desde la protección de tipo clásico, frente al homicidio, hasta la protección frente a los peligros del uso pacífico de la energía atómica. No sólo la vida y la salud son posibles bienes protegidos, sino todo aquello que, desde el punto de vista de los derechos fundamentales, es digno de ser protegido, por ejemplo, la dignidad, la libertad, la familia y la propiedad. No menos variadas son las formas posibles de protección. Ellas comprenden por ejemplo, la protección por medio de normas de derecho penal, de normas de del derecho de la responsabilidad civil, de normas de derecho procesal, de acciones administrativas y por medio de actuaciones fácticas. ${ }^{51}$

Según el mismo profesor de Kiel, lo común detrás de esta variedad es que los derechos de protección son derechos subjetivos constitucionales frente al Estado para que éste realice acciones positivas fácticas o normativas, que tienen como objeto la delimitación de las esferas jurídicas de sujetos jurídicos de igual jerarquía, así como la exigibilidad judicial y la implementación de esta delimitación. De ahí que la existencia de estos derechos planteen las cuestiones de si existen derechos subjetivos de protección o sólo normas que prescriben al Estado la protección de los par-

\footnotetext{
50 Ibidem, p. 436.

51 Ibidem, p. 398.
}

Esta obra está bajo una Licencia Creative Commons

Atribución-NoComercial-SinDerivar 4.0 Internacional, IIJ-UNAM.

Boletín Mexicano de Derecho Comparado, núm. 150, pp. 1215-1258 
ticulares, sin conferirles un derecho subjetivo. Y, en caso de que existan derechos de protección, ¿̇en qué se diferencian de los derechos de defensa de tipo clásico? ${ }^{52}$ Respondamos esta última pregunta.

La doctrina ha dicho que es posible distinguir entre un derecho de defensa y los derechos de protección clásicos: el primero es un derecho frente al Estado a que éste omita intervenciones; los segundos son derechos frente al Estado a que éste se encargue de que terceros omitan intervenciones. Es decir, mientras que los derechos fundamentales, en tanto derechos defensivos, deben rechazar intervenciones injustificadas del poder estatal, el deber de protección derivado de los derechos fundamentales obliga a una intervención del Estado frente a vulneraciones de tales derechos procedentes, no ya del propio Estado, sino de cualquier otra parte. ${ }^{53}$ Debe ponerse la atención en lo siguiente: mientras que los derechos de defensa son, para los obligados, prohibiciones de destruir, de afectar negativamente, etcétera, los derechos prestacionales son, para los obligados, mandatos de proteger o promover algo, etcétera. Si está prohibido destruir o afectar algo, entonces está prohibida toda acción que constituya o provoque una destrucción o afectación. En cambio, si está ordenado proteger o promover algo, no está entonces ordenada toda acción que constituya o provoque una protección o una promoción. Esto, como se verá, resultará muy importante.

Más complicado resulta definir si existe la titularidad de un derecho subjetivo de protección por parte de los individuos a que el Estado los proteja o si, por el contrario, el Estado tiene el deber de proteger a los individuos sin conferirles derecho subjetivo alguno. Este es uno de los problemas centrales en torno a la figura del deber de protección y sobre el que, dicho sea de paso, no existe un consenso en la doctrina ni en la forma que la jurisprudencia constitucional lo ha resuelto. En algunas ocasiones, cuando no resulta tan complicado subjetivar el deber de protección para convertirlo en un derecho subjetivo, la solución ha consistido en esa conversión. Por lo tanto, esto nos advierte de un aspecto relevante: no podemos vincular, sin más, la vertiente objetiva a los derechos a prestaciones, puesto que todos los derechos tienen una dimensión prestacional en sentido amplio.

52 Ibidem, pp. 398 y 399.

53 Von Münch, Igno, "Drittwirkung de derechos fundamentales en Alemania”, trad. de M. Díaz y D. Felip, en Salvador Coderch, P. et al., Asociaciones, derechos fundamentales y autonomía privada, Madrid, Civitas, 1997, p. 45. 
Ahora bien, por lo que respecta a los derechos prestacionales en sentido estricto - o derechos sociales fundamentales, como los denomina Alexy-, conviene tener en cuenta en el plano teórico, la distinción entre derechos y garantías, por un lado, y, por otro, en un plano más dogmático los diversos datos que suministran los ordenamientos jurídicos concretos, es decir, la forma en que fueron estos configurados por el poder político. En el primero de los casos hay que ser consciente de que una cosa es el derecho fundamental y otra distinta son los mecanismos de garantía que se han establecido con la finalidad de tutelarlos. ${ }^{54}$ En este rubro, en el de las garantías, el abanico de posibilidades es bastante generoso; pero además, y esto se vincula con el segundo de los aspectos, la propia configuración de los mecanismos de garantía quizá esté en función de la concepción que de ellos se tenga: si consideramos que los derechos sociales son derechos distintos de los civiles y políticos, podría llevar a pensar a algunos que, en esa medida, se justificaría un tratamiento diferente para los mismos.

De acuerdo con la "existencia" de los derechos sociales o, más específicamente, sobre su carácter jurídico, algunos autores han sostenido que no tendrían tal carácter debido a que no son susceptibles de tutela jurisdiccional y que, por tanto, se trataría de meros "derechos de papel". ${ }^{55}$ Pues bien, a diferencia de quienes sostienen que para la existencia de un derecho fundamental se precisan las respectivas garantías - identificadas con la posibilidad de recabar ante un juez la tutela judicial de los mismos-, en nuestra argumentación cabe la idea de que la existencia de un

54 Esto resulta particularmente significativo para el caso mexicano, donde, durante mucho tiempo, se vinculó el concepto de garantía con el de derecho fundamental, atendiendo al tenor literal del texto constitucional. Una excepción notable la constituye el profesor Fix-Zamudio, quien sostuvo que "la garantía no se concibe más como derecho subjetivo, sino como aquéllos instrumentos que el ordenamiento jurídico ha establecido con la finalidad de tutelar o las disposiciones fundamentales para lograr su restitución cuando hubiesen sido desconocidas o violadas". Véase Fix-Zamudio, Héctor, Introducción al derecho procesal constitucional, México, Fundap, 2002, p. 73.

55 En este sentido, Guastini, Riccardo, "Derechos: una contribución analítica”, trad. de A. Greppi, en Sauca Cano, J. M. (ed.) Problemas actuales de los derechos fundamentales, Madrid, Universidad Carlos III, BOE, 1994, p. 133. Para Guastini, son verdaderos derechos aquellos que satisfacen conjuntamente tres condiciones: a) son susceptibles de tutela jurisdiccional; b) pueden ser reivindicados frente a un sujeto determinado, y c) su contenido consiste en una obligación de conducta bien definida, al igual que el sujeto era su titular. Son derechos de papel - derechos ficticios - todos aquellos que no satisfagan alguna de estas condiciones (ibidem, p. 134).

Esta obra está bajo una Licencia Creative Commons

Atribución-NoComercial-SinDerivar 4.0 Internacional, IIJ-UNAM.

Boletín Mexicano de Derecho Comparado, núm. 150, pp. 1215-1258 
derecho fundamental no depende de aquéllas. ${ }^{56}$ De la misma forma, tal y como ha sido puesto de relieve por la doctrina, nada hay en los derechos sociales que los haga esencialmente distintos que los derechos civiles y políticos. ${ }^{57}$ Las diversas ideas que sostenían aquella diferenciación (que se trata de derechos costosos, que no se puede concretizar su contenido, que no son derechos justiciables, que se trata de derechos que no imponen alguna obligación al Estado, entre otros) resultan de dudosa consistencia..$^{58}$

$\mathrm{Al}$ contrario, a medida que se profundiza en el estudio de esas pretendidas diferencias, se van diluyendo los mitos en torno a los derechos sociales que harían posible si bien no su desaparición como categoría autónoma, por lo menos sí algún tipo de equiparación entre éstos y los derechos civiles y políticos. Análisis rigurosos de la estructura de los derechos sociales, que tienen en cuenta la variedad de significados asignados a ellos (las diversas obligaciones, prohibiciones, competencias, etcétera, que contiene cada derecho de este tipo - o "derechos como un todo", en la terminología de Alexy-) han hecho notar que este tipo de derechos pre-

56 Como se sabe, en esto ha insistido particularmente L. Ferrajoli, quien distingue al menos dos tipos de garantías: las primarias, que se refieren a las propias obligaciones y prohibiciones del derecho fundamental y las secundarias a las obligaciones de reparar o sancionar judicialmente las lesiones de los derechos, es decir, las violaciones de las garantías primarias. De la inexistencia de garantías, según Ferrajoli, no podemos derivar que no se trate de verdaderos derechos fundamentales por no contar con mecanismos de garantía secundaria o judicial. Se trata de "lagunas" que corresponde a los operadores jurídicos denunciar con la finalidad de que se colmen. Escribe Ferrajoli: "frente a la tesis de confusión entre derechos y sus garantías que quiere negar la existencia de los primeros en ausencia de las segundas, sostendré la tesis de la distinción, en virtud de la cual la ausencia de las correspondientes garantías equivale, en cambio, a una inobservancia de los derechos positivamente estipulados, por lo que consiste en una indebida laguna, que debe ser colmada por la legislación". Ferrajoli, Luigi, "Derechos fundamentales", en Cabo, Antonio de y Pisarello, Gerardo (eds.), El fundamento de los derechos fundamentales, 2a. ed., Madrid, Trotta, 2005, p. 26.

57 Rey Pérez, José Luis, "La naturaleza de los derechos sociales", Derechos y Libertades, núm. 16, 2007, pp. 137-156.

58 Holmes, Sthepen y Sunstein, Cass R., The Cost of Rights. Why Liberty Depends on Taxes, Londres-Nueva York, Norton \& Company, 1999, p. 15 (respecto a la importancia de los recursos económicos para la satisfacción de todos los derechos); Abramovich, Víctor y Courtis, Christian, Los derechos sociales como derechos exigibles, 2a. ed., prólogo de L. Ferrajoli, Madrid, Trotta, 2004, p. 37 y ss. (para estrategias de justiciabilidad); y Pisarello, Gerardo, Los derechos sociales y sus garantías. Elementos para una reconstrucción, Madrid, Trotta, 2007, p. 59 y ss. (para un análisis detallado de las supuestas diferencias). 
sentan, en cuanto a la determinación de los sujetos obligados y de las propias obligaciones que imponen, problemas similares a los derechos civiles y políticos. Y lo que es más importante que dependiendo del derecho, ello sería posible - la determinación de alguna obligación que impondría o la identificación del titular de esa obligación-, con lo que se derrumba una de las principales objeciones para hacerlos justiciables o para considerarlos derechos subjetivos en sentido técnico. ${ }^{59}$

Por otra parte, habrá que acudir a los rasgos concretos que cada ordenamiento jurídico concreto nos arroje respecto al sistema de garantías que establezca para los derechos y bienes iusfundamentales. Las distintas posibilidades de configuración de ese sistema se presentan muy amplias para el poder político. Prueba de ello es que el aseguramiento, promoción y disfrute de los derechos puede lograrse con base en distintos métodos y técnicas de garantías, que por supuesto no se agotan en la garantía judicial - y quizá no tengan en ésta el medio más adecuado para hacerlos efectivos- Si bien el disfrute de los derechos depende no sólo de determinadas condiciones políticas y jurídicas, sino también económicas, sociales y culturales, en línea de principio, me parece que puede decirse que una vez que se identifican y se someten a un test más riguroso las diversas críticas de los derechos, queda de manifiesto que quizá el establecimiento de un sistema de garantías disminuidas para los derechos sociales no encuentre suficiente justificación.

Avanzando en este punto y librándonos de esos prejuicios ideológicos, tal vez queden más claros los distintos problemas a resolver con respecto a estos derechos. Debemos considerar que un ordenamiento jurídico que reconozca como principio básico de su organización la igualdad jurídicopolítica de los ciudadanos que integran su comunidad precisa también de la participación de todos los miembros en "igual dignidad". Ello quiere decir que la satisfacción de las necesidades más elementales se convierte, asimismo, en uno de sus presupuestos: sin dicha satisfacción resulta muy difícil plantearse la posibilidad misma de una agencia moral plena o la elección de planes de vida por parte de los individuos. La aptitud para participar - insistimos, en igualdad de condiciones - en la toma de deci-

59 Alexy, Robert, op. cit., nota 11. También puede verse, ampliando la propuesta de este autor, Cruz Parcero, Juan Antonio, El lenguaje de los derechos. Ensayo para una teoría estructural de los derechos, prólogo de F. Laporta, Madrid, Trotta, 2007, pp. 71-100, en especial p. 93. 
siones colectivas que afectan a esos individuos en situaciones de desventaja, miembros de una comunidad política, y a todos sus conciudadanos, quedaría de otra forma severamente cuestionada.

Podría entenderse entonces que el concepto de derecho prestacional es tan amplio y referido a todos los derechos fundamentales que habrá ocasiones en que sea posible adscribir algunos derechos de protección. En estos casos, la dimensión que prevalece es la subjetiva, por lo que no resultaría equiparable del todo con la dimensión objetiva. De ahí que como se ha venido insistiendo a lo largo del presente trabajo, la vertiente objetiva, si se quiere en su sentido más técnico o restringido, se va a referir al deber de protección a cargo del Estado con independencia de que exista violación de algún sujeto y sus derechos en concreto, aun cuando no exista pretensión subjetiva, e inclusive - en el caso más intenso - en contra de la voluntad del titular.

\section{Dimensión objetiva de los derechos fundamentales \\ $y$ "desvinculación" de su titular}

Para poder apreciar de mejor manera la vertiente objetiva, debemos referirnos al deber de protección en su sentido más técnico o restringido, es decir, cuando no sea posible o haya dudas respecto de la subjetivización del mismo. Dicho de otra manera, si existe posibilidad de subjetivizarlo, significa que hay un derecho subjetivo de protección, como menciona Alexy, y que el mismo "encaja perfectamente en la tradición de la comprensión liberal de los derechos fundamentales". ${ }^{60}$ Por tanto, habrá que detenerse en aquellos casos donde se produzca dicha desvinculación por parte de su titular. Acudiré a la jurisprudencia constitucional para tratar de ejemplificar mejor estos supuestos ya que, de no ser así, se corre el riesgo de que este esfuerzo sea una simple exposición insustancial.

El "caso Schleyer" resulta ejemplificativo de la figura de los deberes de protección que se deriva de los derechos fundamentales a cargo del Estado. Durante el llamado "otoño alemán" de 1977, unos terroristas secuestraron a quien por entonces era presidente de la patronal alemana, Hans Martin-Schleyer, amenazando con su ejecución si el gobierno no dejaba en libertad a otros once terroristas encarcelados. El hijo del secuestrado

60 Alexy, Robert, op. cit., nota 11, p. 403. 
solicitó al Tribunal Constitucional la adopción de una medida provisional, intentando salvar la vida de su padre. Dicha medida exigía que el gobierno cumpliera con las exigencias terroristas, liberando a los presos requeridos. En su solicitud argumentó básicamente dos cosas. Por un lado, señaló que el Estado tenía el deber de proteger la vida de su padre, derivado del artículo 2.2 de la Ley Fundamental. Por otro lado, argumentó que las autoridades estatales no pueden dejar que su padre siga corriendo el riesgo inminente de perder la vida a cambio de salvaguardar otros bienes o intereses que las autoridades estimen significativos.

Pues bien, el Tribunal Constitucional había derivado del derecho fundamental a la vida un amplio deber del Estado de proteger toda vida humana, es decir, proteger la vida "incluso frente a agresiones antijurídicas por parte de terceros". No obstante, en el caso concreto del chantaje terrorista, dada la especial singularidad de estas amenazas, el Tribunal determinó que permanecía en manos de los órganos estatales competentes - y no en él- la decisión de cómo reaccionar frente a tales chantajes. Esa solución tenía el antecedente del caso de Peter Lorenz, donde el Estado había cedido inmediatamente a los chantajes de grupos terroristas liberando a varios criminales a cambio de la libertad de Lorenz. Sin embargo, los criminales continuaron vinculados a actos terroristas poniendo en peligro en su totalidad seguridad del país. De hecho, uno de ellos fue miembro del comando que secuestró al propio Schleyer. Esto fue determinante, pues el Tribunal Constitucional Federal rechazó la adopción de la medida provisional. Los terroristas cumplieron su amenaza y asesinaron a Schleyer. ${ }^{61}$ El caso muestra que si bien existe un deber de protección a cargo de los poderes públicos, su margen de discrecionalidad para decidir, en concreto, qué medida o medidas han de tomarse, no es en absoluto desdeñable.

Dos sentencias del contexto español resultan también ilustrativas de los deberes de protección, ya que en ellas se aprecia claramente la desvinculación respecto al titular. La primera es la STC 53/1985 relativa al recurso previo de inconstitucionalidad conocida como la sentencia de la

61 "La resolución (BVerfGE, 46, pp. 260 y ss.) del Tribunal Constitucional - escribe el propio Von Münch - fue una sentencia dura, mortal, y, sin embargo, correcta, porque de otro modo los terroristas habrían sido alentados, precisamente, a la comisión de nuevos secuestros". Von Münch, Igno, op. cit., nota 52, p. 46.

Esta obra está bajo una Licencia Creative Commons

Atribución-NoComercial-SinDerivar 4.0 Internacional, IIJ-UNAM.

Boletín Mexicano de Derecho Comparado, núm. 150, pp. 1215-1258 
"Ley del aborto", en la que sin existir titular de derecho fundamental resultó necesario preservar algunos bienes jurídicos con base en la vertiente objetiva que tiene en cuenta el orden de valores establecido en la Constitución. Ahí se recalca la idea de hacer compatible la dimensión subjetiva de los derechos con la objetiva. Sobre todo, establece la obligación positiva de contribuir a la efectividad de derechos y valores contenidos en la Constitución con independencia de que exista una pretensión subjetiva. ${ }^{62}$

En el segundo caso, la protección del derecho fundamental se realiza aun en contra de la voluntad del titular. ${ }^{63}$ Se trata de la sentencia de 1990 con motivo de la huelga de hambre llevada a cabo por algunos reclusos de los "Grupos de Resistencia Antifascista Primero de Octubre" (GRAPO) a fin de que la administración carcelaria modificara su política de dispersión de los presos terroristas. Pues bien, los reclusos en huelga de hambre intentaban llegar hasta las últimas consecuencias (la muerte), alegando un derecho a la libre configuración de la vida y la muerte con base en la libertad ideológica. Desde su punto de vista, cualquier interferencia de la autoridad - administrando alimentos o medicación forzosamente - sería contraria a la Constitución. Por otro lado, la administración penitenciara alegaba que sobre ella pendía una obligación de protección realizando las acciones necesarias para tutelar la vida de los reclusos que tenía bajo su custodia. Como observa M. G. Barranco Avilés:

...de esta sentencia parece desprenderse que cuando la Constitución española se compromete con la garantía de un derecho fundamental, lo hace con el contenido de ese derecho, que supone la confluencia de un interés privado y del bien común. Puesto que los derechos suelen referirse a bienes en los que está implicado el interés de los sujetos, suelen atribuirse a un titular. Además, se le otorga a este mismo titular la posibilidad de recabar la protección del derecho de los tribunales (en eso consiste la función subjetiva). Sin embargo, los derechos desempeñan un papel esencial para el mantenimiento del orden

62 En esta parte sigo el trabajo de Barranco Avilés, María del Carmen, "El concepto republicano de libertad y el modelo constitucional de derechos fundamentales", Anuario de Filosofia del Derecho, núm. XVIII, 2001, pp. 205-226. Para un análisis más detallado de este caso, y en general sobre el deber de protección involucrado en el mismo, remítase a López Guerra, Luis (ed.), Las sentencias básicas del Tribunal Constitucional, 3a. ed., Madrid, CEPC, 2008, pp. 127 y ss.

63 Barranco Avilés, María del Carmen, "El concepto republicano de libertad...”, cit. p. 207. 
del Estado social y democrático de Derecho, por lo que ese interés individual se protege por su relevancia pública, de forma que no basta con la acción del titular, corresponde a los Poderes Públicos velar por el contenido del derecho que sigue siendo valiosos aun cuando no exista un titular e incluso a pesar de que el titular haya dejado de considerarlo de su interés. ${ }^{64}$

Es decir, el hecho de que una persona esté recluida configura una relación jurídica de especial sujeción, que origina una serie de derechos y deberes recíprocos entre la administración y el recluso. Sobre todo corresponde al Estado velar por la vida, integridad y salud de los reclusos y, en consecuencia, determinadas situaciones como la del caso narrado justificarían la imposición de algunas limitaciones a los derechos fundamentales de los internos que se ponen en peligro de muerte de forma voluntaria. ${ }^{65}$

Parece razonable que el Estado tenga deberes de protección frente a las intervenciones jurídicas de terceros. No obstante, de modo genérico puede afirmarse que la doctrina es casi unánime al señalar que tal deber de protección corresponde en primer lugar, y de modo preponderante, al legislador. Al tratarse de problemas que admiten varias vías de resolución, no es posible ordenar una única y predeterminada actuación para cumplir tales deberes. La discrecionalidad de las autoridades para decidir, su capacidad configuradora, es amplia. Como al Estado en su conjunto le corresponde dicho deber de protección, ello no significa prima facie que la violación de derechos fundamentales provenientes de terceros la cometa el propio Estado. La violación producida en el seno de dichas relaciones no deja de ser una injerencia por parte de terceros; es decir, violaciones en el ámbito de las relaciones entre particulares. Por el contrario, cuando el Estado no ha actuado conforme al deber de protección que le imprimen los derechos fundamentales, o el ordenamiento jurídico no permite subsanar dicha violación valiéndose de los medios de garantía existentes, es posible que de tal deber derive la imputación de la responsabilidad a uno de sus órganos por insuficiencia en la protección.

\footnotetext{
64 Ibidem, p. 217.

65 López Guerra, Luis, op. cit., pp. 154 y ss.
}

Esta obra está bajo una Licencia Creative Commons

Atribución-NoComercial-SinDerivar 4.0 Internacional, IIJ-UNAM.

Boletín Mexicano de Derecho Comparado, núm. 150, pp. 1215-1258 
Finalmente, debe anotarse que el fundamento del deber de protección puede apreciarse desde dos perspectivas. ${ }^{66}$ Para una parte de la doctrina el fundamento se encuentra tanto en el monopolio que el Estado ejerce sobre la violencia, con miras a garantizar la paz social, como en la prohibición de que los ciudadanos puedan ejercer violencia alguna por sí mismos. ${ }^{67}$ Para otro sector de la doctrina, el fundamento se encontraría en la propia estructura de los derechos fundamentales en su dimensión objetiva, y por la cual ya no sólo son oponibles al Estado, "sino que el bien jurídico constitucionalmente protegido hace parte de la personalidad de su titular, teniendo pretensión de validez universal, frente a cualquier amenaza o lesión". ${ }^{68}$

\section{LA VIGENGIA DE LOS DEREGHOS FUNDAMENTALES}

EN LAS RELACIONES ENTRE PARTICULARES

La vigencia entre particulares de los derechos fundamentales es otro de los llamados "hijos legítimos" de la vertiente objetiva o de su validez en todos los ámbitos del derecho. Se trata del efecto frente a terceros o Drittwirkung der Grundrechte, según la denominación realizada por H. P. Ipsen en la doctrina alemana de mediados del siglo pasado. ${ }^{69}$ Aquí van a aparecer

66 Julio Estrada, Alexei, La eficacia de los derechos fundamentales entre particulares, Bogotá, Universidad Externado de Colombia, 2000, pp. 74 y ss.

67 "El fundamento decisivo del deber de protección es visto en consagración del Estado como ordenamiento de la paz, que reclama para sí el monopolio del poder, y significa para los particulares el deber de obediencia y la prohibición del uso la fuerza privada. La renuncia del derecho natural a la defensa de los bienes jurídicos propios sólo puede tener significado cuando se sabe que dichos bienes son asegurados por el Estado. Entonces, la garantía de seguridad es presupuesto del sometimiento, sólo la protección estatal legitima la renuncia al uso de la fuerza privada. De este modo, el deber estatal de protección sería consecuencia de la necesidad de garantizar la protección de la convivencia pacífica; por lo tanto, si el estado no garantizara la protección de las libertades fundamentales no habría seguridad, y existiría el peligro en que el individuo amenazado en sus bienes jurídicos se procure el «derecho» por sí mismo". (Ibidem, p. 76).

68 Ibidem, p. 77.

69 La expresión se la atribuye Igno von Münch a dicho autor ("Drittwirkung de derechos fundamentales en Alemania...", cit., en la nota el pie número 6, en la p. 28). En México, el desarrollo más completo del tema, hasta donde tengo conocimiento, lo encontramos en Mijangos y González, Javier, Los derechos fundamentales en las relaciones entre particulares. Análisis del caso mexicano, México, Porrúa, 2007. 
referencias a la idea de colisión entre derechos fundamentales o principios - al encontrarnos ante un conflicto que enfrenta a dos titulares de derechos fundamentales-, y también a la ponderación para la solución de este tipo conflictos.

Por ello, el tratamiento adecuado de este tema parte de identificar, al menos, los dos principales problemas que presenta y que precisan atenderse de forma separada. Me refiero al problema de la vigencia de los derechos fundamentales entre particulares, por un lado, y el problema de la eficacia de los mismos, por el otro. ${ }^{70} \mathrm{El}$ primero se refiere a la manera en que los derechos fundamentales inciden en las relaciones entre particulares, mientras que el segundo, a la protección o al mecanismo de tutela para hacerlo efectivo. Es lo que se ha identificado como el "problema sustancial" y el "problema procesal" de la Drittwirkung. No en pocas ocasiones este tema suele complicarse aún más por entremezclar éstos, que son objeto de análisis distintos.

Aquí interesa el primer problema - el relativo a la incidencia de los derechos fundamentales en las relaciones entre particulares - que ha sido resuelto por dos vías supuestamente distintas, las cuales han dado origen a dos teorías: la de la eficacia mediata (Mittelbare Drittwirkung) y la de la inmediata (Unmittelbare Drittwirkung). Señalo "supuestamente distintas" porque se cuestiona si, efectivamente, las vías mencionadas son contrapuestas o contradictorias, porque apuntando a diversos operadores jurídicos ambas conducen a resultados similares; es decir, que son "equivalentes en sus resultados". ${ }^{71}$ En la medida en que esto sea cierto, parece ajustada la observación de que en la actualidad lo que se discutiría no es la forma en que se construye la Drittwirkung - a través de las diversas teorías-, sino el propio efecto frente a terceros. ${ }^{72}$ En cualquier caso, me interesa presentar ambas posiciones (eficacia mediata e inmediata), pues considero que cada una introduce matices y, sobre todo, en el fondo late la misma idea: si se

70 Peces-Barba, Gregorio, Curso de derechos fundamentales. Teoría general, con la colaboración de R. de Asís, C. Fernández Liesa y A. Llamas, Madrid, Universidad Carlos III-BOE, 1995, pp. 618 y 619.

71 Alexy, Robert, op. cit., nota 11, pp. 471 y 472.

72 No me detendré en esta cuestión. Para las diversas posturas que niegan el efecto frente a terceros, véase Bilbao Ubillos, Juan María, La eficacia de los derechos fundamentales frente a particulares. Análisis de la jurisprudencia del Tribunal Constitucional, prólogo de J. Jiménez Campo, Madrid, CEPC-BOE, 1997, pp. 278 y ss.

Esta obra está bajo una Licencia Creative Commons

Atribución-NoComercial-SinDerivar 4.0 Internacional, IIJ-UNAM.

Boletín Mexicano de Derecho Comparado, núm. 150, pp. 1215-1258 
postula la fuerza normativa de los contenidos constitucionales resulta muy difícil negar que los derechos tengan vigencia en las relaciones entre particulares. El problema radicaría en determinar cómo y en qué medida se formula dicha vigencia.

Mucho tiene que ver en la determinación del alcance del efecto frente a terceros la principal crítica que se le formula: que con él, el principio de autonomía de la voluntad, en la que se cimienta todo el derecho privado, corre el riesgo de socavarse sobre la base de dicha construcción. El riesgo se encontraría en la posible suplantación del derecho privado por las normas constitucionales que, además de indeseable, resultaría peligrosamente nociva. En efecto, desde este punto de vista se pondrá en alerta sobre el hecho de que la Constitución no tiene a su cargo regular directamente las relaciones entre particulares y que en caso de que fuera así, además, se perdería la distinción entre Estado y sociedad.

\section{La teoría de la eficacia mediata}

Para la teoría de la eficacia mediata, los derechos fundamentales actúan en las relaciones entre particulares, no como derechos subjetivos directamente oponibles, sino como principios que en su carácter objetivo precisan ser "rellenados"73 para introducir en las normas de derecho privado el contenido de los derechos fundamentales. Así, se afirma que los derechos fundamentales obligan a los particulares sólo indirectamente, como decisiones valorativas objetivas que se proyectan sobre el conjunto del ordenamiento y, en esa medida, vinculan al legislador y al juez: no son los actos de los sujetos privados, sino las normas de derecho privado las que están directamente relacionadas con los derechos fundamentales. Por lo tanto, los derechos sólo obligan de forma inmediata a los actos de los poderes públicos, y en ningún caso a los particulares. ${ }^{74}$

${ }^{73}$ La expresión la tomo de Starck, Christian, "Derechos fundamentales y derecho privado", trad. de M. J. Roca, Revista Española de Derecho Constitucional, núm. 66, 2002, p. 67.

74 Venegas Grau, María, Derechos fundamentales y derecho privado. Los derechos fundamentales en las relaciones entre particulares y el principio de autonomía de la voluntad, prólogo de R. de Asís, Madrid, Marcial Pons, 2004, p. 114. 
El principal defensor de esta teoría fue Gunter Dürig. ${ }^{75}$ Para este autor, la garantía de la dignidad humana contenida en la Ley Fundamental de Bonn no se limita a establecer una obligación negativa a cargo del Estado, sino que - según Dürig - impone un deber de protección y de tutela frente a cualquier injerencia que la lesione, sin importar su origen. En la medida en que la Constitución contempla los derechos fundamentales como realización más eficaz de esa protección de los valores en el ámbito del derecho positivo, de ello se deriva que los valores protegidos frente al Estado a través de los derechos también deben ser protegidos cuando son vulnerados por sujetos privados o colectivos sociales. ${ }^{76}$ Esta protección no pasa por la aplicación directa de los derechos fundamentales en el tráfico jurídico-privado, pues ello limitaría excesivamente el principio de autonomía de la voluntad, garantizado también por la Constitución. Según Dürig, las obligaciones que recaen con el Estado en relación con los derechos fundamentales no se pueden trasladar sin más a los particulares que como sujetos jurídico-privados tienen la facultad de "decidir libremente si y cómo van a hacer uso de la libertad y de la igualdad, sin tener en cuenta cuáles son las obligaciones y las prohibiciones que en este ámbito le impone el Estado". ${ }^{77}$ Por ello, la proyección horizontal de los derechos debe realizarse a través de la mediación del legislador y, en su defecto, del juez.

En esta construcción - que fue la que imperó en Alemania a partir del fallo Lüth-, se observa que los derechos fundamentales no pueden tener el mismo impacto en las relaciones ciudadano-ciudadano, pues se trata aquí de relaciones entre titulares de derechos fundamentales a los que, de entrada, se les reconoce su capacidad de autodeterminación. Por ello, y a pesar de la influencia del derecho fundamental, las normas de derecho privado deberían seguir siendo normas de derecho privado, así como los derechos y deberes por ellas fundamentados. De ahí que se precise la mediación, ya sea del juez o del legislador, para hacerlos efectivos en el tráfico jurídico privado. Son ellos a quienes los derechos fundamentales obligan

75 Su trabajo seminal es "Grundrechte und Zivilrechtsprechung", en Vom Bonner Grundgesetz zur gesamtsdeutschen Verfaßung. Festschrift zum 75. Geburgstag von Hans Nawiasky, Múnich, Beck, 1956.

76 Cit. por Venegas Grau, María, op. cit., nota 74, p. 116.

77 Idem. Véanse Julio Estrada, Alexei, op. cit. nota 66, p. 109, y Cruz, Luis Manuel, La Constitución como orden de valores. Problemas jurídicos y políticos, Granada, Comares, 2005, pp. 21 y ss.

Esta obra está bajo una Licencia Creative Commons

Atribución-NoComercial-SinDerivar 4.0 Internacional, IIJ-UNAM.

Boletín Mexicano de Derecho Comparado, núm. 150, pp. 1215-1258 
de forma inmediata, y quienes tienen a su cargo, a través de su dimensión objetiva, el deber de protección de los mismos; pero no obligan directamente, en ninguna circunstancia, a los actos de los particulares.

Como puede apreciarse, la afectación del concepto "clásico" de autonomía de la voluntad está en el centro de la polémica de la Drittwirkung. En su concepción tradicional, nos dice M. Venegas Grau, el principio de autonomía de la voluntad, estructurador del derecho privado desde el siglo XIX, afirma la capacidad jurídica de cada individuo de regular libremente sus relaciones con los demás. Esta idea tendría su base en una teoría individualista que consideraba al individuo abstracto como una voluntad libre, aislado del medio social, como único objeto, fundamento y fin del derecho. ${ }^{78}$ Ahora se entienden las acotaciones que, teniendo presente la construcción de Dürig, se formulan sobre la eficacia mediata: la exigencia de mediación del legislador y del juez permite a los defensores de esta teoría preservar la libertad de las partes, pues se cree que esta teoría parece la única compatible con el principio de autonomía de la voluntad. De ahí que esta formulación tendría en cuenta la especificidad del sujeto jurídicoprivado, por lo que propone una articulación satisfactoria de los derechos con aquel principio.

La articulación de la doctrina de la eficacia mediata - al no reconocer la violación por parte de un particular del derecho fundamental de otro-, precisa imputar dicha violación a un poder público, generalmente a la decisión del juez que conoce del conflicto. Se trata de la tesis de la "imputación judicial" —o la "asunción judicial", para J. M. Bilbao Ubillos - ${ }^{79}$ de la vulneración, que utilizada por primera vez en el fallo Lüth sigue siendo practicada hasta nuestros días. Conforme a la misma, la vulneración de los derechos fundamentales no es imputable al particular ni tiene origen en una relación interprivados, sino que la ocasiona el juez

78 Derechos fundamentales y derecho privado, op. cit., p. 33. No obstante, como ha puesto de manifiesto la propia autora, dicha concepción parece más artificiosa y puede desmentirse ya desde su origen mediante un análisis histórico riguroso; pero sobre todo, a la luz de su configuración actual.

79 El catedrático de la Universidad de Valladolid denomina de esta manera dicha teoría. Sin embargo, consideramos que la denominación correcta es la manejada por Alexei Julio Estrada, pues, efectivamente el juzgador "no asume" la violación de los derechos fundamentales, sino que la misma "le es imputada".

Esta obra está bajo una Licencia Creative Commons Atribución-NoComercial-SinDerivar 4.0 Internacional, IIJ-UNAM. Boletín Mexicano de Derecho Comparado, núm. 150, pp. 1215-1258 
cuando al aplicar el derecho ordinario para decidir un conflicto entre particulares lesiona derechos fundamentales. ${ }^{80}$

\section{La teoría de la eficacia inmediata}

La doctrina de la eficacia inmediata afirma que la vinculación a los derechos fundamentales corresponde - con matices y de forma diferenciada - también a los particulares. Con ella se postula que las relaciones privadas están sujetas de forma automática a las disposiciones que contienen los derechos fundamentales, o en palabras de J. M. Bilbao Ubillos: "afirma la virtualidad directa, sin mediaciones concretizadoras, de los derechos fundamentales en tanto derechos subjetivos reforzados por la garantía constitucional, frente a las violaciones provenientes de los particulares". ${ }^{81}$ La tesis fue formulada originalmente por H. C. Nipperdey, ${ }^{82}$ quien fuera presidente del Tribunal Federal de Trabajo alemán, a la luz del precepto que establece la igualdad salarial entre hombres y mujeres. Según Nipperdey, determinados derechos fundamentales rigen de manera directa en el tráfico jurídico privado, sin necesidad de algún intermediario. El autor tuvo muy claro desde la formulación de su teoría algunas de las posibles objeciones a las que debía hacer frente. Así, comienza por introducir la distinción entre aquellos derechos fundamentales que pueden tener vigencia en las relaciones entre particulares, de aquellos que por su propia estructura puedan vincular únicamente al Estado. Por lo tanto, no pretende una validez absoluta e indiferenciada de todos los derechos en las relaciones entre particulares.

Ésta es una objeción atendible, ya que en no pocas ocasiones se critica a los defensores de la Drittwirkung directa por postular un efecto absoluto. Nada más lejano a la realidad. Desde el comienzo, los partidarios de esta postura tenían claro que ello era imposible: dada la propia diversidad de derechos fundamentales, habrá algunos que estén dirigidos exclusiva-

80 Estrada, Alexei Julio, op. cit., nota 66, pp. 172 y 173.

81 Bilbao Ubilllos, Juan María, op. cit., nota 66, p. 325. En sentido similar, Rafael Naranjo de la Cruz (Los limites de los derechos fundamentales en las relaciones entre particulares: la buena fe, Madrid, CEPC, 2000, p. 215) considera que "las normas de derechos fundamentales contenidas en la Constitución generan derechos subjetivos de los ciudadanos oponibles tanto a los poderes públicos como a los particulares".

82 "Gleicher Lohn der Frau für gleiche Leistung”, Recht der Arbeit, núm. 4, abril de 1950.

Esta obra está bajo una Licencia Creative Commons

Atribución-NoComercial-SinDerivar 4.0 Internacional, IIJ-UNAM.

Boletín Mexicano de Derecho Comparado, núm. 150, pp. 1215-1258 
mente a vincular al poder público en sus relaciones con los particulares, habrá otros que, efectivamente, puedan tener incidencia también en las relaciones individuo-individuo. ${ }^{83}$ Por ello podría decirse que, en definitiva, no se ha postulado una eficacia indiferenciada de todos los derechos fundamentales en el ámbito privado; es decir, no se ha postulado un efecto entre particulares de los derechos fundamentales, sino una Drittwirkung de derechos fundamentales en donde así lo admitan. ${ }^{84}$

Nipperdey observa, además, que según ha sido reconocido por el Tribunal de Karlsruhe en el fallo Lüth, los derechos presentan una vertiente objetiva, que en su carácter objetivo de principio informan a todo el ordenamiento jurídico, modelando de esta forma las relaciones de los individuos en sociedad. Así, la Drittwirkung "aparece como la consecuencia lógica de las transformaciones que implica el concepto de Estado social, en especial la primacía del interés general sobre las motivaciones particulares y la realización efectiva del mandato de igualdad". ${ }^{85}$ Según Nipperdey, una vez reconocido que el sistema de derechos y valores contenido en la Ley Fundamental debe regir para todos los ámbitos del derecho, resulta contradictorio que posteriormente se afirme que dicha influencia se ejerce por medio del ius cogens y de las cláusulas generales del Código Civil alemán. Dicho reconocimiento supone "reconocer el efecto normativo directo de los derechos fundamentales sobre el Derecho Privado". ${ }^{86}$

Ya se opte por la eficacia inmediata o mediata, al final, lo que importa es que se acepte la vigencia de los derechos en las relaciones privadas y

83 Nipperdey formula las siguientes precisiones que fortalecen su postura: en primer lugar es necesario verificar "si tan siquiera cabe contemplar el derecho fundamental en el ámbito jurídico privado", si es así, se pasa a continuación a apreciar debidamente la "finalidad protectora y el orden que contiene" la norma en cuestión; y de acuerdo con el ámbito de protección que requiera dicha finalidad se determina a su vez la extensión de protección entre los particulares. Cit. por Julio Estrada, Alexei, op, cit., nota 66, p. 97.

84 Von Münch, Igno, op. cit., nota 52, p. 35.

85 Estrada, Alexei Julio, op. cit., nota 66, pp. 104 y 105.

86 Según Nipperdey: "el Orden jurídico forma una unidad y todo derecho tan solo rige en base y en el marco de la Constitución... Para que los derechos fundamentales a modo de normas objetivas, rijan en el derecho privado, no se requiere de ningún medio, ningún punto de infiltración, como lo pretenden ser las cláusulas generales. Antes bien el efecto jurídico es uno directo y normativo, que modifica o regenera las normas jurídico privadas existentes, sean derecho imperativo o dispositivo, cláusulas generales o normas jurídicas determinadas, trátese de prohibiciones, mandatos, derechos subjetivos, derechos de protección o causas de justificación”. Cit. por Estrada, Alexei Julio, op. cit., nota 66, p. 106. 
que se tenga la posibilidad de hacerlos efectivos. Alguna parte de la doctrina acepta que los resultados alcanzados en el marco de una pueden alcanzarse en el de la otra, fundamentalmente, por sus conexiones y semejanzas. Sus semejanzas radican en que ambas precisan de la actividad judicial para que se produzca la eficacia en el tráfico jurídico privado; ambas tienen en cuenta la recíproca titularidad de derechos fundamentales por las partes en conflicto en una relación de derecho privado. Las dos se oponen por igual a las soluciones generales y favorecen el análisis de las circunstancias fácticas del caso; y lo que es más relevante: al final, para ambas teorías, la solución de un caso litigioso se transforma en un problema de ponderación a cargo de los tribunales de los bienes iusfundamentales en conflicto. ${ }^{87}$

Sin embargo, si se acepta la fuerza vinculante de la Constitución, considero que debe estarse al efecto directo frente a terceros, pues la misma vendría a ser algo así como límite y frontera de su normatividad. Por lo demás, como ha argumentado M. Venegas Grau, la actual configuración del principio de autonomía de la voluntad dista mucho de tener - aún en sus orígenes - las características que se le atribuyen: en el marco del Estado social y democrático de derecho, dicho principio comprende algunos criterios materiales de justicia que pretenden asegurar la libertad efectiva de los individuos a la hora de vincularse jurídicamente con otros individuos. En su configuración actual, escribe Venegas Grau: "el principio de autonomía de la voluntad se encuentra al servicio de la libertad real que pretende consolidarle no sólo frente a las injerencias públicas sino también en las relaciones privadas". ${ }^{88}$

La Drittwirkung se muestra como un instrumento poderoso en el marco del Estado social y democrático de derecho para que la igual libertad y autonomía de los miembros de la sociedad pueda obtenerse. Nuevamente en el ámbito del derecho de contratos, los derechos adquirirán una dimensión objetiva con lo que, de alguna manera, aquél se subordina a los segundos. La eficacia de los derechos en el ámbito privado tiene como finalidad salvaguardar el orden constitucional y de principios establecidos —notablemente en la corrección de desigualdades fácticas-, exista o no

87 Alexy Robert, op. cit., nota 11, pp. 471 y ss., y Estrada, Alexei Julio, op. cit., nota 66, p. 127.

88 Venegas Grau, María, op. cit., nota 74, p. 228.

Esta obra está bajo una Licencia Creative Commons

Atribución-NoComercial-SinDerivar 4.0 Internacional, IIJ-UNAM.

Boletín Mexicano de Derecho Comparado, núm. 150, pp. 1215-1258 
pretensión subjetiva o aun en contra de la voluntad de los particulares. En el llamado caso del agente comercial (Handelsvertretrer) de 1990 hay una muestra clara de ello.

En ese caso, el Tribunal Federal Constitucional alemán invalidó un contrato que establecía una cláusula entre un agente comercial y el representante de una empresa por la cual, básicamente, se estableció una prohibición o incompetencia del primero para contratar posteriormente. El Tribunal consideró que establecer la imposibilidad absoluta para que el agente comercial pudiera contratar durante los siguientes dos años a partir de la fecha de la terminación de su contrato generaba una situación heterónoma; o lo que es lo mismo, la pérdida de su autonomía a manos de la empresa. Asimismo, el contrato establecía que en caso de que hubiera terminación anticipada por culpa del agente, este último no tendría derecho a indemnización alguna. A juicio del Tribunal era clara la desigualdad fáctica entre los contratantes: la posición de preponderancia de la empresa sobre el agente era de tal magnitud que, a efectos prácticos, tales cláusulas anularon la libertad contractual del agente. Es aquí donde precisamente deben intervenir los tribunales, quienes tienen una obligación de proteger los derechos fundamentales y, sobre todo, de restaurar el equilibrio perdido a resultas de la desigualdad material. Si bien el fundamento de la intervención lo constituye la figura del deber de protección, en este caso no operaría frente a intrusiones provenientes de terceros, sino que se trata de una protección frente a las restricciones de las libertades iusfundamentales aceptadas voluntariamente por la parte contratante más débil. O como dice A. Julio Estrada, "en resumidas cuentas, de la protección frente a uno mismo". ${ }^{89}$

Nos encontramos ante un caso de clara colisión entre derechos fundamentales y el principio de autonomía de la voluntad. En lo que concierne a esa relación, de la decisión transcrita se desprende que los tribunales, si bien respetando en lo sustancial la autonomía privada, deben extraer límites de los derechos fundamentales ahí donde exista la especial necesidad de protección de una de las partes del negocio jurídico; así por ejemplo, cuando a uno de los contratantes no se le puede exigir que vele de forma autorresponsable por la defensa de sus propias posiciones iusfundamentales debido a su libertad contractual está visiblemente limitada o afectada

89 Estrada, Alexei Julio, op. cit., nota 66, pp. 202 y 203.

Esta obra está bajo una Licencia Creative Commons Atribución-NoComercial-SinDerivar 4.0 Internacional, IIJ-UNAM. Boletín Mexicano de Derecho Comparado, núm. 150, pp. 1215-1258 
o porque los presupuestos funcionales de la autonomía privada no están garantizados. ${ }^{90}$

\section{A MODO DE CONCLUSIÓN}

La asignación de una vertiente objetiva a los derechos fundamentales, así como los desarrollos vinculados a ella - fundamentalmente la Drittwirkung-, constituyen sin género de duda, "uno de los descubrimientos jurídicos más importantes de los tiempos modernos" y que ha convertido la dogmática constitucional alemana en "auténtico artículo de exportación jurídica" ${ }^{91}$ En su origen, esa doble dimensión estuvo muy próxima a la teoría de la integración, a la idea de que los derechos constituyen "un orden objetivo de valores" (Objektive Wertordnung), tal y como señalara el Tribunal Constitucional alemán. Sin embargo, con el paso del tiempo esa caracterización ha ido cediendo paso a la idea de que los derechos fundamentales son principios, sobre todo en la influyente teoría de R. Alexy. De esta forma, la teoría de los principios puede, por un lado, articular, sin pérdida de capacidad explicativa, el carácter expansivo de los derechos en todo el ordenamiento jurídico a la vez que, por el otro, prescinde de la noción más comprometida y problemática de "valor".

En segundo lugar, podría concluirse que la idea de una doble dimensión o de una dimensión valorativa de los derechos fundamentales sirve para articular un discurso específico a propósito del derecho. Ese discurso cuestiona la rígida separación entre Estado y sociedad característica del constitucionalismo burgués. De hecho, uno de los objetivos de crítica preferidos desde tal posición es la doctrina liberal burguesa de los derechos que, debido a las peculiaridades y circunstancias en la que se fue gestando, ${ }^{92}$ puso énfasis en la esfera de libertad de los individuos, en el carácter prejurídico y preestatal de los derechos fundamentales. Todo ello se concretó en ordenamientos jurídicos que dieron prevalencia al principio de autonomía de la voluntad, que constituye un punto de partida inne-

90 Idem.

91 Von Münch, Igno, op. cit., nota 52, pp. 29 y 30.

92 Grimm, Dieter, "Los derechos fundamentales en relación con el origen de la sociedad burguesa", trad. de R. Sanz, en id., Constitucionalismo y derechos fundamentales, estudio preliminar de A. López Pina, Madrid, Trotta, 2006, pp. 77-106.

Esta obra está bajo una Licencia Creative Commons

Atribución-NoComercial-SinDerivar 4.0 Internacional, IIJ-UNAM.

Boletín Mexicano de Derecho Comparado, núm. 150, pp. 1215-1258 
gable para considerar a los individuos iguales (formalmente) ante la ley. Por el carácter expansivo de los derechos y la doctrina de la Dritwirkung, no obstante, se abre una "puerta" para revisar la legitimidad del uso de la autonomía individual, es decir, si lo pactado no lesiona la igual dignidad de los contratantes; o si lo acordado no contraviene el orden de valores establecido en la Constitución. Es la así llamada "constitucionalización" del derecho privado.

La figura de los deberes de protección, por su parte, sirve como campo de prueba para analizar hasta qué punto la salvaguarda del derecho fundamental se desvincula del poder de decisión de su titular. Aquí hay que enfatizar el margen de apreciación y de configuración específica que tienen los poderes públicos, fundamentalmente el legislador, para satisfacer y colmar dichos deberes de protección a la luz de las particularidades que pueden venir al caso. La desvinculación de su titular se hace patente en los casos ya analizados y puede ejemplificarse con la idea de la "protección frente a uno mismo". Si tenemos en cuenta que los derechos desempeñan un papel esencial para el mantenimiento del orden del Estado social y democrático de derecho, los derechos han de salvaguardarse también en consideración a su relevancia pública (su valor para todo el sistema) y no sólo teniendo en cuenta el interés individual. De ahí que corresponda a los poderes públicos del Estado velar por el contenido del derecho, que sigue siendo valioso aun cuando no exista un titular, e incluso a pesar de que el titular haya dejado de considerarlo de su interés.

Esto nos introduce de lleno en la problemática más acusada de dicha "doble configuración" de los derechos fundamentales: la posibilidad de que la dimensión subjetiva pueda ser "absorbida" por la objetiva. Es decir, de que unos presupuestos más comunitaristas se afiancen sobre los elementos individualistas, o liberales, de nuestra concepción del derecho y de la sociedad. Plantea, asimismo, la problemática de una eventual pérdida de libertad de los individuos en manos de un Estado abocado a una deriva paternalista. Ser conscientes de tal posibilidad y de sus nefastas consecuencias para una sociedad libre plantea el imperativo de estar alerta de cualquier deriva totalitaria del derecho en nombre de los derechos mismos. Por último, soy consciente de que cualquier estudio de los derechos fundamentales necesita analizar la configuración de sus normas y sus relaciones en posibles casos de colisión. Para ello es indispensable estudiar las peculiaridades de su estructura principal (la distinción entre principios 
y reglas), el problema de los límites de los derechos, así como el tratamiento de sus posibles restricciones por parte del legislador donde el recurso a la proporcionalidad resulta necesario. Sin embargo, prefiero dejar esa tarea para mejor ocasión. ${ }^{93}$

Fecha de recepción: 07 de diciembre de2016

Fecha de aceptación: 18 de mayo de 2017

93 Mi deuda con la doctora María del Carmen Barranco Avilés por su guía en la elaboración de este trabajo es inmensa. Agradezco también a Alicia I. Saavedra-Bazaga, quien no sólo me ha animado a someter este artículo al dictamen de la comunidad académica sino que, como siempre, me ha ayudado a mejorarlo. Las carencias que presenta son de mi entera responsabilidad.

Esta obra está bajo una Licencia Creative Commons

Atribución-NoComercial-SinDerivar 4.0 Internacional, IIJ-UNAM.

Boletín Mexicano de Derecho Comparado, núm. 150, pp. 1215-1258 